\title{
Ochratoxin A-induced autophagy in vitro and in vivo promotes porcine circovirus type 2 replication
}

\author{
Gang Qian ${ }^{1,2}$, Dandan Liu ${ }^{1,2}$, Junfa Hu, ${ }^{1,2}$, Fang Gan ${ }^{1,2}$, Lili Hou ${ }^{1,2}$, Xingxiang Chen ${ }^{*, 1,2}$ and Kehe Huang, ${ }^{*, 1,2}$
}

Ochratoxin A (OTA) is a mycotoxin produced by Aspergillus and Penicillium. Porcine circovirus type 2 (PCV2) is recognized as the causative agent of porcine circovirus-associated diseases. Recently, we reported that low doses of OTA promoted PCV2 replication in vitro and in vivo, but the underlying mechanism needed further investigation. The present studies further confirmed OTAinduced PCV2 replication promotion as measured by cap protein expression, viral titer, viral DNA copies and the number of infected cells. Our studies also showed that OTA induced autophagy in PK-15 cells, as assessed by the markedly increased expression of microtubule-associated protein 1 light chain 3 (LC3)-II, autophagy-related protein 5 (ATG5), and Beclin-1 and the accumulation of green fluorescent protein (GFP)-LC3 dots. OTA induced complete autophagic flux, which was detected by monitoring p62 degradation and LC3-II turnover using immunoblotting. Inhibition of autophagy by 3-methylademine (3-MA) and chloroquine (CQ) significantly attenuated OTA-induced PCV2 replication promotion. The observed phenomenon was further confirmed by the knock-down of ATG5 or Beclin- 1 by specific siRNA. Further studies showed that $\mathrm{N}$-acetyl-L-cysteine (NAC), an ROS scavenger could block autophagy induced by OTA, indicating that ROS may be involved in the regulation of OTA-induced autophagy. Furthermore, we observed significant increases in OTA concentrations in lung, spleen, kidney, liver and inguinal lymph nodes (ILN) and bronchial lymph nodes (BLN) of pigs fed 75 and $150 \mu \mathrm{g} / \mathrm{kg}$ OTA compared with controls in vivo. Administration of $75 \mu \mathrm{g} / \mathrm{kg}$ OTA significantly increased PCV2 replication and autophagy in the lung, spleen, kidney and BLN of pigs. Taken together, it could be concluded that OTA-induced autophagy in vitro and in vivo promotes PCV2 replication.

Cell Death and Disease (2017) 8, e2909; doi:10.1038/cddis.2017.303; published online 29 June 2017

Porcine circovirus type 2 (PCV2) is a small, non-enveloped, single standard circular DNA virus belonging to the genus Circovirus of the Circoviridae family. ${ }^{1}$ PCV2 is the primary causative agent of several diseases that are collectively referred to as porcine circovirus-associated diseases (PCVAD). However, not all pigs infected with PCV2 develop PCVAD, and other factors, such as animal management, viral infections, immune stimulation and nutrition, have been suggested to be associated with the disease. ${ }^{2}$

Ochratoxins are a group of mycotoxins produced principally by ubiquitous strains of Aspergillus and Penicillium. ${ }^{3,4}$ Ochratoxin A (OTA), the most prevalent ochratoxin. ${ }^{5}$ Owing to its natural origin, pervasiveness at low levels and chemical stability, OTA contamination persists throughout the feed supply and the food chain. ${ }^{3,6}$ Our previous work suggests that OTA may be an important trigger of PCV2 replication and that the varying levels of OTA in pig feed may partially explain why the morbidity and severity of PCVAD vary among PCV2infected pig farms. ${ }^{7}$ However, the underlying mechanism through which OTA promotes PCV2 replication requires further investigation.

Autophagy is a conserved catabolic intracellular process through which long-lived proteins and damaged organelles are degraded by the lysosomal machinery. ${ }^{8,9}$ Autophagy not only plays an essential role in cellular homeostasis but also participates in numerous other physiological and pathological processes. ${ }^{10}$ Normally, autophagy acts as a defense mechanism against viral infection. ${ }^{11-13}$ Interestingly, several types of viruses exploited the autophagic processes to enhance their own replication. ${ }^{13-15}$ Few data involving autophagy, OTA and viral infection have been reported to date.

In the present study, we investigated the role of autophagy in OTA-promoted PCV2 replication in vitro and in vivo, thereby developing potential novel antiviral strategies against PCV2 infection.

\section{Results}

Cytotoxic effects of OTA on PK-15 cells. To determine whether the effect of OTA on PCV2 replication results from OTA induction of cell toxicity or alteration in the energy supply of PK-15 cells, we examined the effects of OTA on cell viability using the 3-(4,5-dimethyl-2-thiazolyl)-2,5-diphenyl-2$\mathrm{H}$-tetrazolium bromide (MTT) and ATP assays. As shown in Figure $1 \mathrm{a}$, the viability of PK-15 cells was not affected by OTA up to a concentration of $2 \mu \mathrm{M}$, but at concentrations of 5 and $10 \mu \mathrm{M}$, OTA significantly lowered $(P<0.05)$ the cell viability of PK-15 cells. A similar reduction in intracellular ATP levels after treatment of the cells with OTA was observed (Figure 1b). Thus, in subsequent experiments, OTA was used at concentrations between 0.01 and $2 \mu \mathrm{M}$.

${ }^{1}$ College of Veterinary Medicine, Nanjing Agricultural University, Nanjing 210095, Jiangsu Province, China and ${ }^{2}$ Institute of Nutritional and Metabolic Disorders in Domestic Animals and Fowls, Nanjing Agricultural University, Nanjing 210095, Jiangsu Province, China

${ }^{*}$ Corresponding author: K Huang or X Chen, College of Veterinary Medicine Nanjing Agricultural University College of Veterinary Medicine, Nanjing Agricultural University, Nanjing 210095, Jiangsu Province, China. Tel: +86 25 84395507; Fax: +86 25 84398669; E-mail: khhuang@njau.edu.cn or cxx@njau.edu.cn

Received 01.3.17; revised 19.5.17; accepted 29.5.17; Edited by GM Fimia 

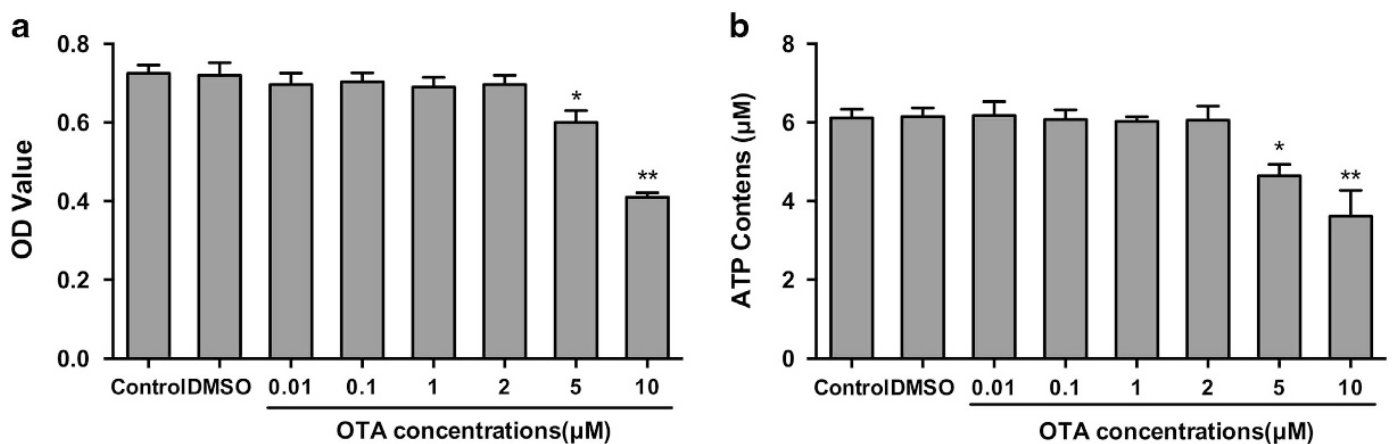

Figure 1 Effect of ochratoxin A (OTA) on the cell viability and ATP contents of PK-15 cells. PK- 15 cells were seeded in 96 -well plates at a density of $5 \times 10^{3}$ cells/well or in 24-well plates at a density of $4 \times 10^{4}$ cells/well and cultured in the presence of $0.01,0.1,1,2,5$, or $10 \mu \mathrm{M}$ OTA for $48 \mathrm{~h}$. (a) Cell viability was determined by MTT assay. (b) Intracelluar ATP concentrations were determinded using a luciferase-based ATP assay kit. The data are presented as means \pm S.E. of three independent experiments. Statistical significance compared with the control is indicated by ${ }^{*} P<0.05$ and ${ }^{*} P<0.01$

OTA promotes PCV2 replication in PK-15 cells. To determine the effect of OTA on PCV2 replication, PK-15 cells were infected with PCV2 for $24 \mathrm{~h}$ and then incubated with OTA at concentrations between 0.01 and $2 \mu \mathrm{M}$ for an additional $48 \mathrm{~h}$. As shown in Figure 2, exposure of cells to the solvent control, dimethyl sulfoxide (DMSO), had no effect on PCV2 replication. However, treatment with $0.01,0.1,1$ or $2 \mu \mathrm{M}$ OTA significantly $(P<0.05)$ increased the cap protein level (Figure 2a), viral titer (Figure 2b), PCV2 DNA copies (Figure 2c) and the number of PCV2-infected cells (Figure 2d) compared with the control group. The maximal effects were observed at $0.1 \mu \mathrm{M}$ OTA.

OTA increases autophagosome formation in PK-15 cells. To determine whether OTA induces autophagy in PCV2-infected PK-15 cells, we examined the levels of autophagy marker proteins using Western blotting. LC3, which is necessary for the formation and maturation of the autophagosome, is a hallmark for assessing autophagy. ${ }^{16,17}$ Our results showed that treatment with OTA led to a significant upregulation of LC3-II expression (Figure 3a). We next examined the expression of ATG5, an essential protein that is associated with the formation of the autophagosomes membranes. ${ }^{18}$ OTA-treated cells displayed significantly increased levels of ATG5 relative to control cells (Figure 3a). We further measured the levels of Beclin-1, a protein involved in the early steps of the autophagy pathway. ${ }^{19,20}$ Similar results were also observed in that OTA treatment induced the overexpression of Beclin-1 relative to control cells (Figure 3a). The maximal effects of OTA on the expression of autophagic markers were observed at an OTA concentration of $0.1 \mu \mathrm{M}$.

To further analyze whether the autophagy machinery was triggered by OTA treatment, PK-15 cells were transfected with green fluorescent protein-microtubule-associated protein 1 light-chain 3 (GFP-LC3), a specific marker of autophagic vesicles and autophagic activity. ${ }^{21,22}$ As shown in Figure 3b, OTA treatment significantly increased the number of GFP-LC3 puncta compared with the control group, with the maximal effect observed at an OTA concentration of $0.1 \mu \mathrm{M}$. These findings indicate that OTA induces autophagy in PCV2infected PK-15 cells.
OTA treatment increases autophagic flux. To determine whether a complete autophagic flux is occurred by OTA treatment, we investigated the degradation of p62. ${ }^{22-24}$ As shown in Figure $4 a$, the level of p62 protein in PK-15 cells decreased significantly with time during OTA treatment.

Since enhanced autophagosome accumulation could be caused either by increased autophagosome formation or by decreased autophagosome turnover, ${ }^{25}$ the levels of LC3-II and p62 were measured in the presence of the lysosomal protease inhibitor $C Q .{ }^{26}$ As demonstrated in Figure $4 \mathrm{~b}, \mathrm{CQ}$ treatment significantly increased the levels of LC3-II and p62 in OTA-treated PK-15 cells, suggesting that OTA treatment enhanced autophagic flux in the cells.

Pharmacological inhibition of autophagy reduces OTApromoted PCV2 replication in PK-15 cells. To evaluate the role of autophagy in OTA-promoted PCV2 replication in PK-15 cells, the effect of 3-MA, which inhibits autophagy by blocking the formation of autophagosomes, ${ }^{27,28}$ on OTApromoted PCV2 replication was examined. Figure 5 shows that treatment with 3-MA reduced the level of cap protein (Figure 5a), viral titers (Figure 5b), PCV2 DNA copies (Figure $5 c$ ) and the number of infected cells (Figure $5 d$ ), compared with the control group and that is attenuated the promotion of PCV2 replication by $0.1 \mu \mathrm{M}$ OTA (Figures $5 \mathrm{a}-\mathrm{d}$ ).

Similarly, CQ, an inhibitor of autophagic flux, was utilized to inhibit the late stage of autophagy. ${ }^{29}$ As demonstrated in Figure 6, CQ treatment significantly decreased the expression of cap protein (Figure 6a), viral titers (Figure 6b), PCV2 DNA copies (Figure 6c) and the number of infected cells (Figure 6d) compared with the control group, it also decreased the promotion of PCV2 replication by $0.1 \mu \mathrm{M}$ OTA (Figures $6 \mathrm{~b}-\mathrm{e}$ ).

The results of these pharmacological experiments demonstrated that autophagy has a positive effect on OTA-promoted PCV2 replication.

Knockdown of autophagy-related genes (ATGs) reduces OTA-promoted PCV2 replication. To exclude any nonspecific effects in our pharmacological experiments, we further examined the effect of reducing the levels of the intracellular autophagy proteins ATG5 and Beclin-1 on the 
a

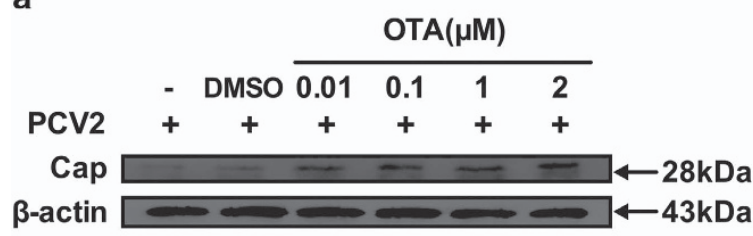

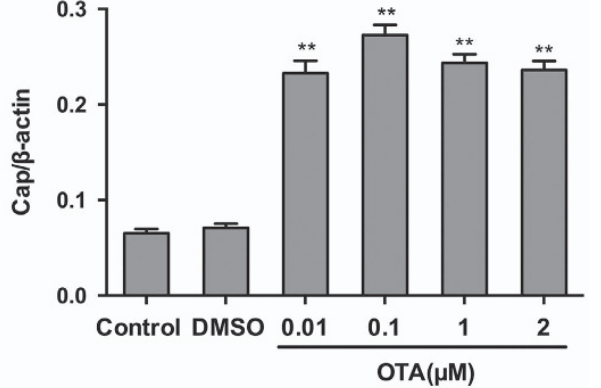

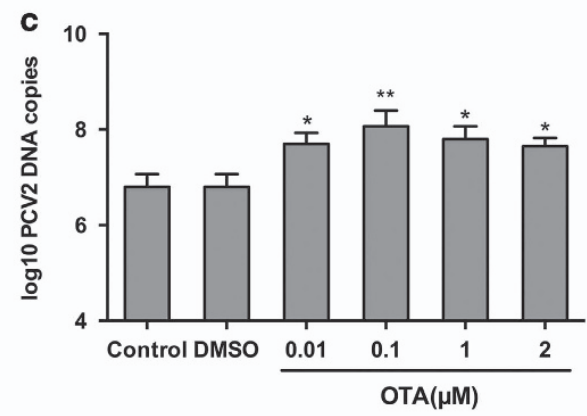

b
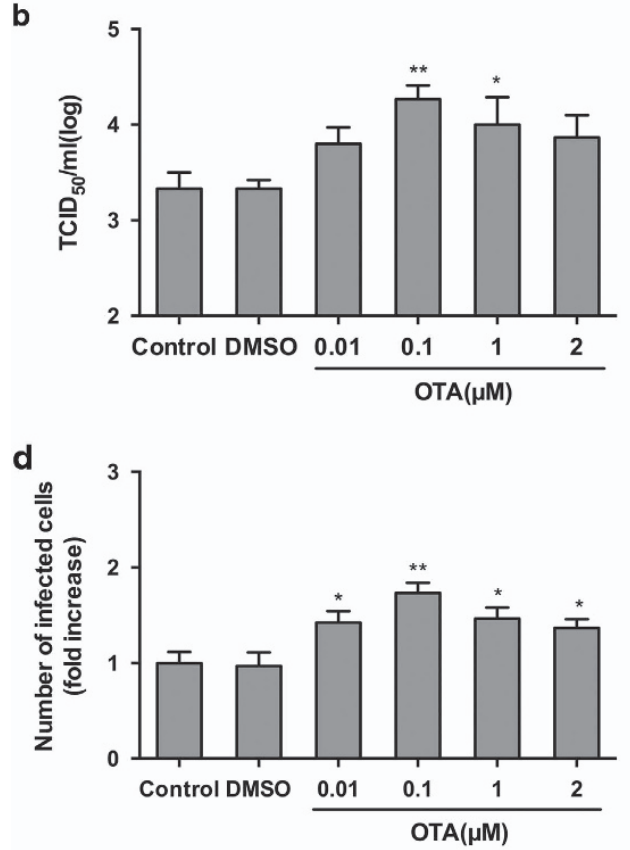
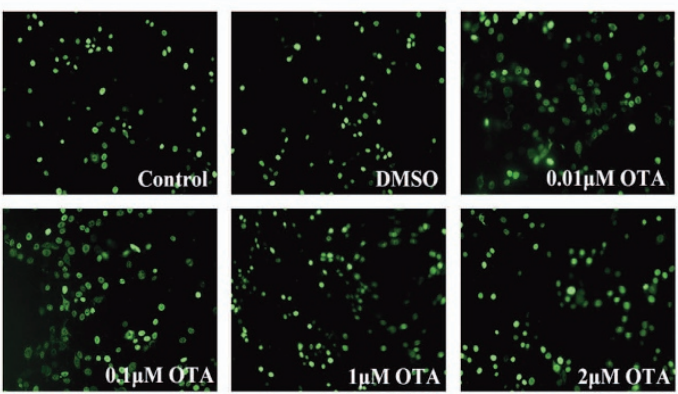

Figure 2 OTA promotes PCV2 replication in PK-15 cells. PK-15 cells were infected with PCV2 for $24 \mathrm{~h}$ and then treated with OTA at concentrations of $0.01,0.1,1$, or $2 \mu \mathrm{M}$ for an additional $48 \mathrm{~h}$. The cells were then collected and assayed for (a) PCV2 viral cap protein expression by western blotting, (b) viral titer by IFA, (c) PCV2 viral DNA copies by qRTPCR, and (d) the number of infected cells by IFA, as described in the Materials and Methods section. The data are presented as means \pm S.E. of three independent experiments. Statistical significance compared with the control is indicated by ${ }^{*} P<0.05$ and ${ }^{* *} P<0.01$

replication of PCV2 promoted by OTA, using target-specific RNA interference. As shown in Figures $7 a$ and $8 \mathrm{a}, \mathrm{PK}-15$ cells transfected with siATG5 and siBeclin-1 displayed significantly decreased expression levels of the ATG5 and Beclin-1 proteins compared with cells transfected with ssiRNA and with the control group. As shown in Figures 7 and 8 , significant reduction in viral cap protein expression (Figures 7b and 8b), viral titers (Figures 7c and 8c), PCV2 DNA copies (Figures 7d and 8d) and the number of infected cells (Figures $7 e$ and $8 e$ ) in cultures of PK-15 cells transfected with siATG5 or siBeclin-1 without or with treatment of OTA were observed. These results are in agreement with the results of previous pharmacological studies. Taken together, these results further support the idea that autophagy is required for OTA-promoted PCV2 replication.

OTA induces autophagy via ROS induction. To assess the role of ROS in OTA-induced autophagy, we first determined whether ROS accumulate after the treatment of cells with
OTA and whether the commonly used ROS inhibitor NAC inhibits ROS production. FACS analysis revealed an increase in the mean DCFH-DA fluorescence after the treatment of the cells with OTA (Figure 9a). Similar results were observed in cells stained with DCFH-DA and examined by confocal microscopy. As shown in Figure 9b, DCFH-DA fluorescence significantly increased after OTA treatment, whereas NAC could significantly decrease OTA-induced ROS production (Figures 9a and b). As shown in Figure 9b, the majority of the green fluorescence (DCFH-DA staining) was localized in the mitochondria after OTA treatment, indicating that mitochondria are the major sources of intracellular ROS. To verify that OTA-induced autophagy is associated with ROS induction, the level of autophagy was determined in the presence or absence of NAC. As shown in Figures $9 \mathrm{c}$ and $\mathrm{d}$, OTA significantly increased $(P<0.05)$ the expression levels of LC3-II, ATG5 and Beclin-1 and the formation of GFP-LC3 puncta. However, pretreatment with NAC markedly attenuated the induction of autophagy by OTA. These results 

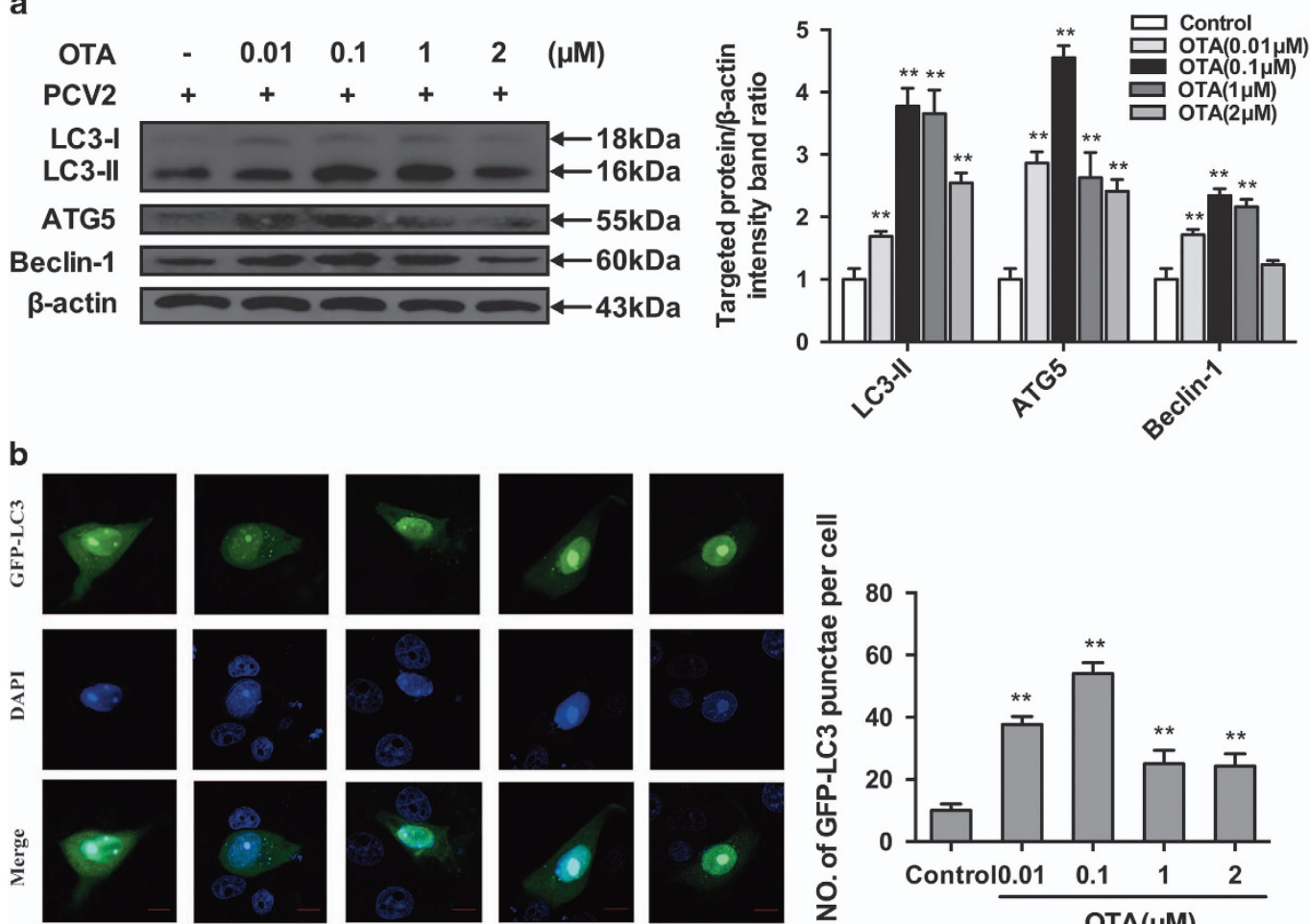

0.01

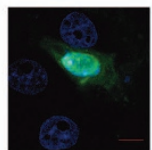

0.1

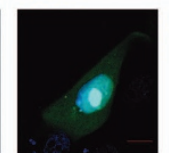

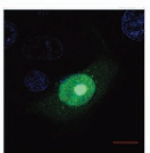

2

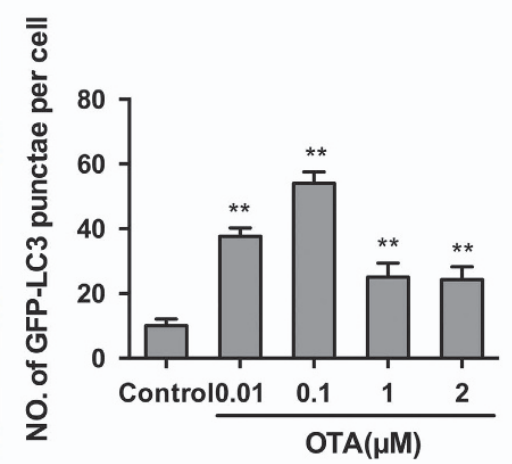

Figure 3 OTA induces autophagy in PK-15 cells. (a) PK-15 cells were inoculated with PCV2 for $24 \mathrm{~h}$, OTA was then added at concentrations of $0.01,0.1,1$, or $2 \mu \mathrm{M}$, and incubation was continued for an additional $48 \mathrm{~h}$. After collecting the cells, the expression of LC3, ATG5, Beclin-1 and $\beta$-actin (loading control) was analyzed by immunoblotting with specific antibodies as described in Materials and Methods. The data are presented as means \pm S.E. of three independent experiments. Statistical significance compared with the control is indicated by ${ }^{*} P<0.05$ and ${ }^{* \star} P<0.01$. (b) PK-15 cells were first transfected with the GFP-LC3 plasmid. After $12 \mathrm{~h}$, the cells were inoculated with PCV2 for $24 \mathrm{~h}$, then, OTA was added at a concentration of $0.01,0.1,1$, or $2 \mu \mathrm{M}$, incubation was continued for $48 \mathrm{~h}$, and the fluorescence signal was visualized by confocal immunofluorescence microscopy. Scale bar: $10 \mu \mathrm{m}$. The average number of LC3 puncta in each cell was determined from at least 100 cells in each group. The data are presented as means \pm S.E. of three independent experiments. Statistical significance compared with the control is indicated by ${ }^{\star} P<0.05$ and ${ }^{* \star} P<0.01$

indicate that OTA-induced autophagy was mediated by ROS induction.

Alteration of autophagy does not affect cell viability. To assess whether the pharmacological alteration of autophagy with 3-MA and CQ or transfection with siRNA or NAC affected PCV2 replication by changing the cell viability, the effects of our pharmacological treatments or siRNA transfection or NAC on PK-15 cell viability were analyzed using the MTT assay. Statistical analyses showed no significant differences $(P>0.05)$ on the viability of cells treated with agents or siRNA transfection (Figure 10).

OTA treatment in vivo. We further evaluated the effects of OTA on PCV2 infection in an animal model and determined whether autophagy can also be induced in vivo. As Figure 11a shows, no OTA was detected in the tissues from the control group, whereas OTA concentrations were significantly increased in the tissues of pigs fed an OTAcontaminating diet. The levels of OTA vary from 0.04 to $0.12 \mu \mathrm{g} / \mathrm{g}$ in the tissues of the animals in the $75 \mu \mathrm{g} / \mathrm{kg}$ OTA group and from 0.08 to $0.16 \mu \mathrm{g} / \mathrm{g}$ in the tissues of the animals in the $150 \mu \mathrm{g} / \mathrm{kg}$ OTA group. These concentrations are similar to concentrations of OTA that promoted PCV2 replication in the in vitro experiment.

Next, we determined the PCV2 viral loads in the tissues of the three groups of pigs using qRT-PCR. Figure $11 \mathrm{~b}$ shows that, compared with the pigs in the control group, significant increases in PCV2 DNA copies were found in the lungs, spleens, and kidneys of the pigs treated with $75 \mu \mathrm{g} / \mathrm{kg}$ OTA and in the bronchial lymph nodes (BLN) of the pigs treated with 75 and $150 \mu \mathrm{g} / \mathrm{kg}$ OTA. We also analyzed the PCV2 viral cap protein levels in the tissues of all the animals by Western blotting. We observed that the lungs, spleens, kidneys, and BLN of the pigs treated with $75 \mu \mathrm{g} / \mathrm{kg}$ OTA contained significantly higher expression levels of cap protein (Figure 11e). These in vivo results are consistent with the in vitro data showing that relatively low doses of OTA could promote PCV2 replication.

Serum SOD activity and serum MDA content were measured following the treatment of the animals with OTA. As shown in Figures $11 \mathrm{c}$ and d, following the feeding of OTAcontaining diets, significant reductions in SOD activities compared with those in the control group were observed in the $75 \mu \mathrm{g} / \mathrm{kg}$ OTA group on day 42 and in the $150 \mu \mathrm{g} / \mathrm{kg}$ OTA group on days 28 and 42, whereas slight reductions in SOD activity were observed on days 14 and 28 in the $75 \mu \mathrm{g} / \mathrm{kg}$ OTA 
a
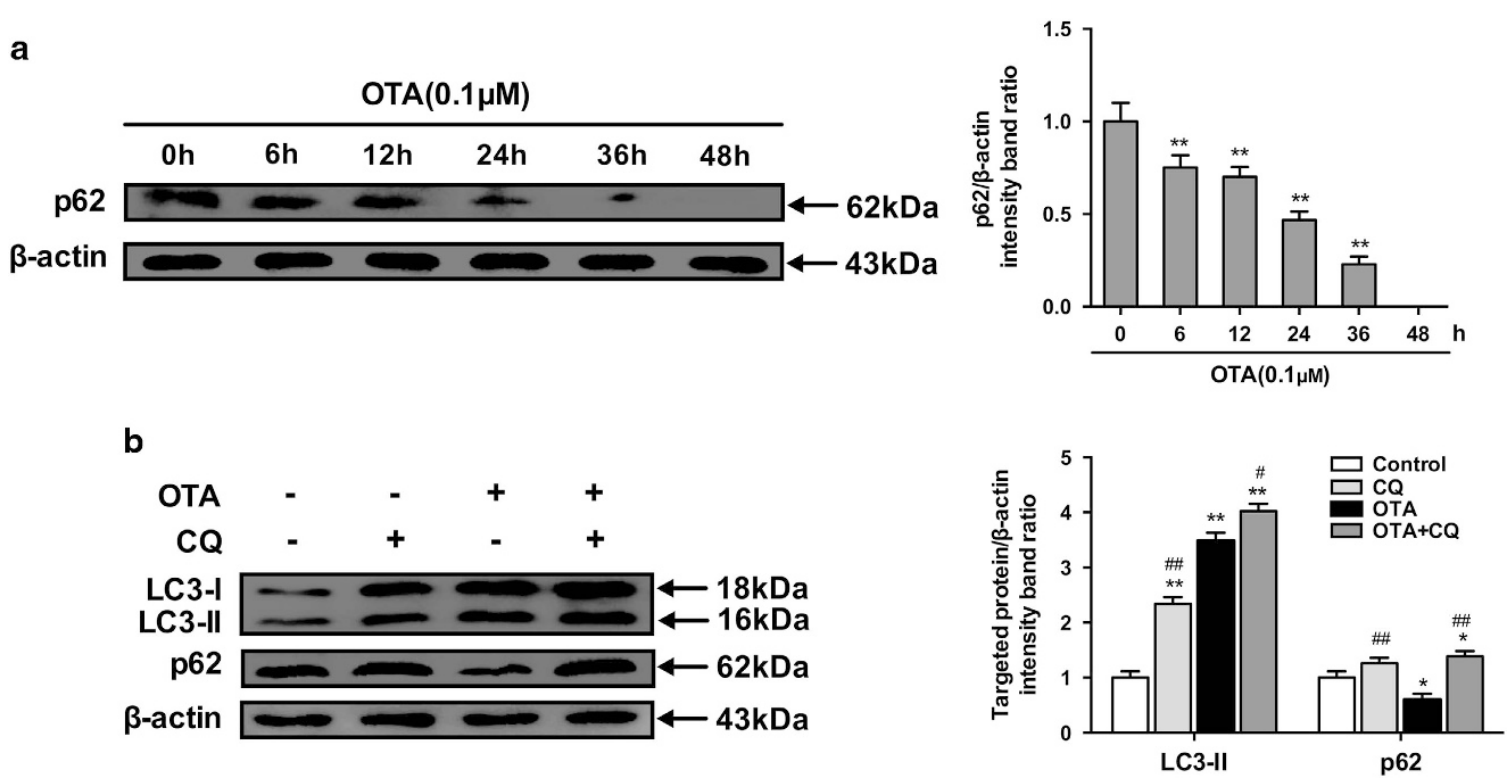

Figure 4 OTA treatment enhances autophagic flux. (a) PK-15 cells were inoculated with PCV2 for $24 \mathrm{~h}$ and then inculated with OTA $(0.1 \mu \mathrm{M})$. At the indicated times after inoculation, the cells were collected, and the expression of p62 and $\beta$-actin (loading control) was analyzed by immunoblotting with specific antibodies as described in Materials and Methods. The data are presented as means \pm S.E. of three independent experiments. Statistical significance compared with the control is indicated by ${ }^{*} P<0.05$ and ${ }^{* *} P<0.01$. (b) PCV2-infected PK-15 cells were incubated with OTA $(0.1 \mu \mathrm{M}), \mathrm{CQ}$ or with OTA and CQ for $48 \mathrm{~h}$. After collecting the cells, the expression of LC3, p62 and $\beta$-actin (loading control) was analyzed by immunoblotting with specific antibodies as described in Materials and Methods. The data are presented as the mean \pm S.E. of three independent experiments. Statistical significance compared with the control is indicated by ${ }^{\star} P<0.05$ and ${ }^{* \star} P<0.01$. Statistical significance compared with OTA is indicated by ${ }^{\#} P<0.05$ and ${ }^{\# \#} P<0.01$

group and on day 14 in the $150 \mu \mathrm{g} / \mathrm{kg}$ OTA group (Figure 11c). In addition, significant increases in MDA levels were observed in both OTA-fed groups on days 28 and 42, whereas slight increases were observed on day 14 (Figure 11d).

We also measured the autophagy levels in the tissues of OTA-fed animals by measuring the LC3-II/ $\beta$-actin ratio in the tissues. Figure $11 \mathrm{e}$ shows that the LC3-II/ $\beta$-actin ratio increased significantly in the lungs, spleens, and kidneys of pigs treated with $75 \mu \mathrm{g} / \mathrm{kg}$ OTA and in the BLN of pigs treated with 75 and $150 \mu \mathrm{g} / \mathrm{kg}$ OTA, compared with pigs that received basal diet. The LC3-II/ $\beta$-actin ratios in the examined tissues were generally consistent with the viral infection levels in those tissues.

Overall, these results indicated that low doses of OTA could promote PCV2 replication and induce oxidative stress, and active autophagy in vivo.

\section{Discussion}

The presence of mycotoxins derived from naturally occurring fungal metabolites in feed and foodstuffs of humans and animals is unavoidable. Owing to their widespread presence in the environment, mycotoxins often co-exist with other infectious agents such as viruses, bacteria and other pathogens and may increase the susceptibility to these infectious agents. OTA is a natural contaminant of farm animal feeds worldwide and poses a potential threat to animal production. ${ }^{30}$ Among farmed animals, pigs are particularly sensitive to OTA and are frequently exposed to this mycotoxin. PCV2 is an emerging viral disease that is a major concern for pig health and has significant economic impact on the swine industry, but the morbidity and severity of PCVAD vary among pig farms. ${ }^{31,32}$ Numerous cofactors have been shown to contribute to the development of PCVAD. Our previous work suggests that OTA may be an important trigger of PCV2 replication and that the varying levels of OTA in pig feed may partly explain the difference in the morbidity and severity of PCVAD vary among pig farms. ${ }^{7}$ However, the underlying mechanisms of OTA-promoted PCV2 replication require further investigation.

Autophagy is an evolutionarily ancient pathway that plays essential roles in host defenses against viral infection and cell survival ${ }^{33,34}$ for instance, it is involved in cellular defenses against herpes simplex virus and mosaic virus infections. ${ }^{35,36}$ In contrast, many viruses exploit the autophagy machinery to enhance their own replication. ${ }^{11,13,14}$ Mycotoxins have generally not been associated with autophagy. Recently, however, mycotoxins such as patulin, zearalenone and OTA have been linked to autophagy. ${ }^{34,37,38}$ Based on recent findings concerning the interplay between mycotoxin, autophagy and viral infection, an autophagic mechanism appears to be involved in OTA-promoted PCV2 replication. In this study, we determined the role of autophagy in OTA-promoted PCV2 replication. Our results reveal a novel mechanism by which ROS-mediated autophagy induced by OTA contributes to PCV2 infection both in vitro and in vivo.

In the present study, the viability of PK-15 cells was significantly decreased by OTA at concentrations above $2 \mu \mathrm{M}$, consistent with previous studies. ${ }^{39,40}$ As shown in Figure 1, no cell cytotoxicity or change in ATP contents was observed at OTA concentrations between 0.01 and $2 \mu \mathrm{M}$; however, PCV2 replication was significantly promoted 

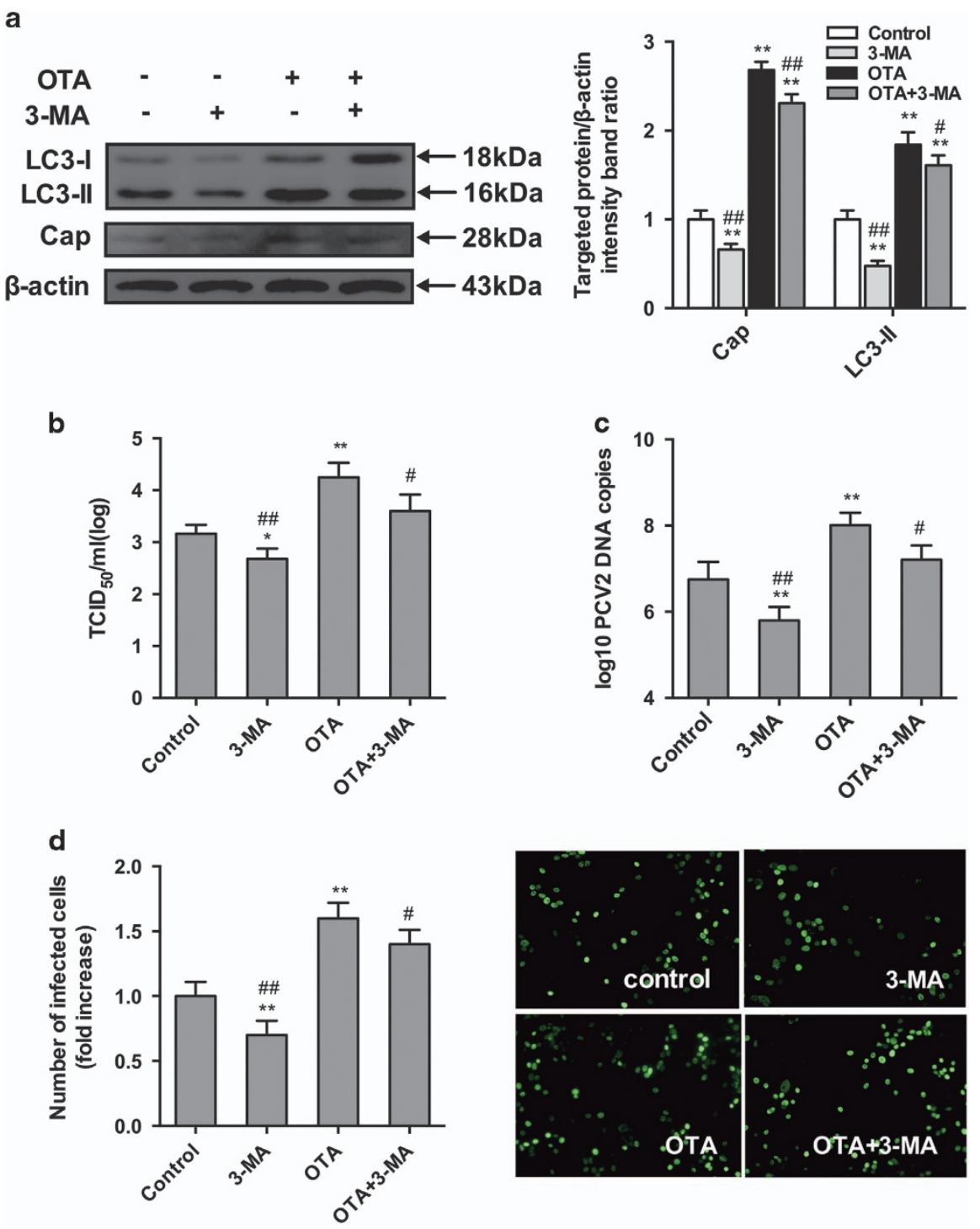

Figure 5 Inhibition of autophagy with 3-MA reverses PCV2 replication induced by OTA in PK-15 cells. PCV2-infected cells were incubated with OTA (0.1 $\mu$ M) with or without 3-MA (5 mM). The cells were then assayed for (a,b) expression levels of LC3, Cap and $\beta$-actin (loading control), (c) PCV2 viral titers, (d) PCV2 viral DNA copies and (e) the number of infected cells, as described in Materials and methods. The data are presented as means \pm S.E. of three independent experiments. Statistical significance compared with the control is indicated by ${ }^{*} P<0.05$ and ${ }^{* *} P<0.01$. Statistical significance compared with OTA is indicated by ${ }^{\#} P<0.05$ and ${ }^{\#} P<0.01$

by OTA (Figure 2), and maximal promotion of PCV2 replication was observed at $0.1 \mu \mathrm{M}$ OTA. The results further confirmed that low doses of OTA promote PCV2 replication in $\mathrm{PK}-15$ cells $^{7}$ and that the promotion of PCV2 replication observed in these experiments was due to OTA exposure.

In the present study, we provide evidence that nontoxic concentrations of OTA induce autophagy in PCV2infected PK-15 cells through increased expression of LC3-II, ATG5, and Beclin-1. Consistently, a large number of cytoplasmic autophagosomes were observed by confocal fluorescence microscopy in OTA-treated PK-15 cells, further confirming that autophagy was induced by OTA. However, previous studies have demonstrated that the induction of autophagy involves not merely an increase in the formation of autophagosomes, but also an increase in autophagic flux. ${ }^{26}$ P62 degradation is a method that is widely used to assess autophagic flux. ${ }^{23,41}$ In our study, we found that the p62 expression level was significantly decreased in PCV2-infected PK-15 cells after the treatment with OTA over a prolonged period of time. We also measured the levels of LC3-II and p62 in the presence or absence of lysosome inhibitor $C Q$. Treatment with $\mathrm{CQ}$ could lead to a $\mathrm{pH}$ shift in the, thus inhibiting lysosomal acidification. Figure $4 \mathrm{~b}$ shows that treatment of PK-15 cells with OTA decreased the p62 expression level in the cells and that treatment with $C Q$ increased the amounts of LC3-II and p62 in OTA-treated cells, indicating that the accumulation of autophagosomes in OTA treated PCV2-infected PK-15 cells was due to the increased autophagy flux. 

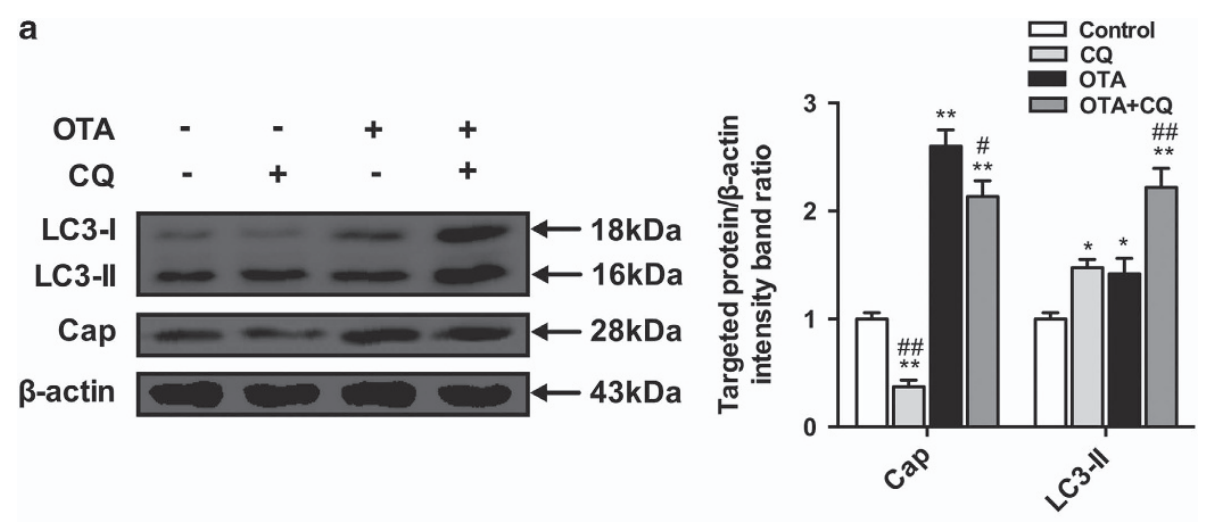

b
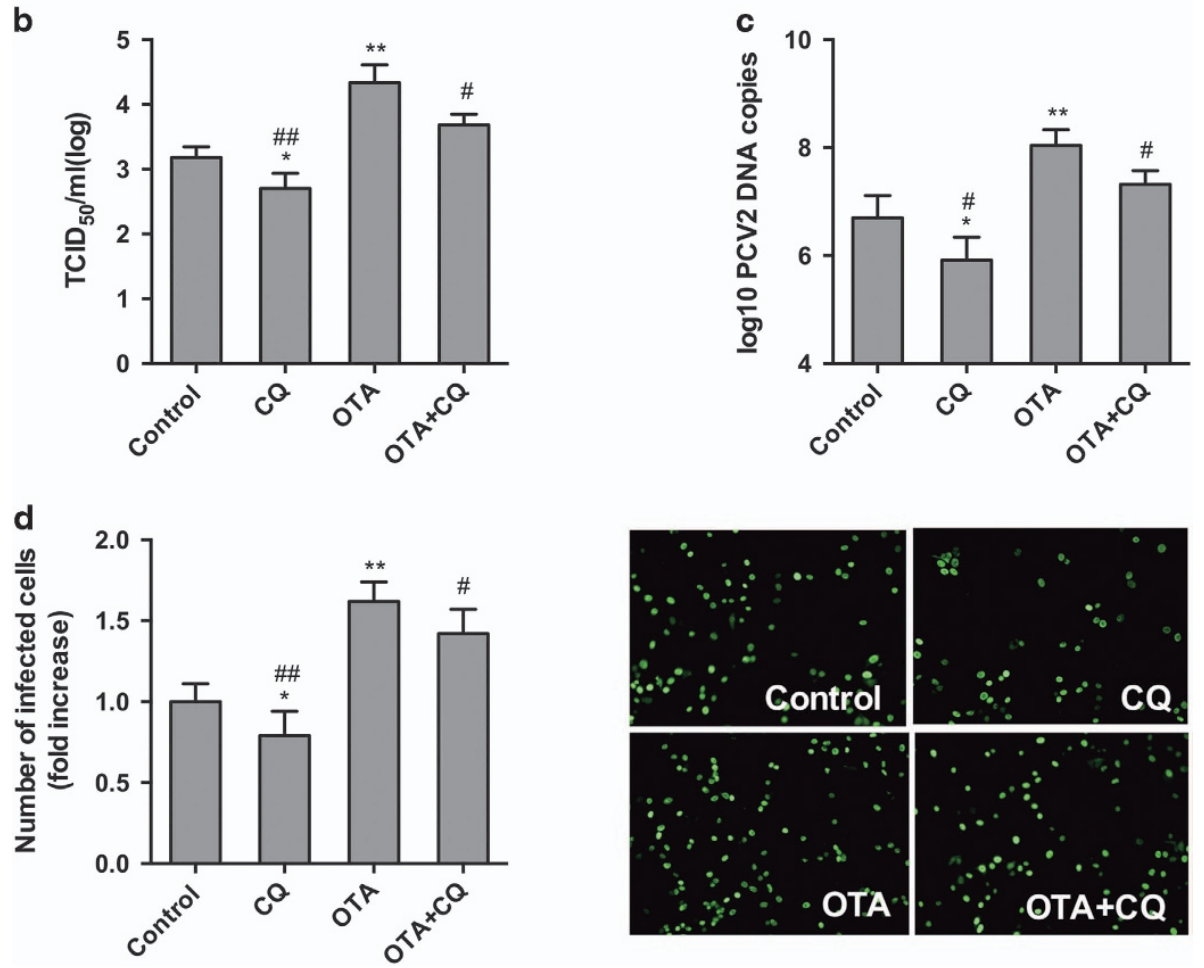

Figure 6 Inhibition of autophagy by CQ reverses PCV2 replication promotion induced by OTA in PK-15 cells. PCV2-infected cells were incubated with OTA (0.1 $\mu$ M) with or without CQ $(5 \mu \mathrm{M})$. Cells were assayed for $(\mathbf{a}, \mathbf{b})$ expression levels of LC3, Cap and $\beta$-actin (loading control), (c)PCV2 viral titers, (d) PCV2 viral DNA copies and (e) the number of infected cells as described in Materials and Methods. The data are presented as means \pm S.E. of three independent experiments. Statistical significance compared with the control is indicated by ${ }^{*} P<0.05$ and ${ }^{* *} P<0.01$. Statistical significance compared with OTA is indicated by ${ }^{\#} P<0.05$ and ${ }^{\# \#} P<0.01$

Previous studies have shown that many viruses, including poliovirus, coxsackievirus B4, hepatitis $\mathrm{C}$ virus, dengue virus, and PCV2, utilize components of the autophagic pathway to facilitate their replication. ${ }^{14,15,42-44}$ However, the role of autophagy in OTA-promoted PCV2 replication has not been previously investigated.

To determine the role of autophagy in OTA-promoted PCV2 replication, PK-15 cells were treated with 3-MA and CQ, which are pharmacological inhibitors of autophagy. ${ }^{45,46}$ These compounds inhibited PCV2 replication and reduced the replication of PCV2 promoted by OTA, consistent with previous studies showing that PCV2 replication was significantly reduced by $3-\mathrm{MA}^{14}$ and that NDV replication was significantly reduced by $C Q .{ }^{47}$
To further confirm the pharmacological data and exclude any non-specific effects of these pharmacological agents used in our experiments, we used target-specific RNA interference to examine the effect of reducing the levels of essential autophagy proteins ATG5 and Beclin-1 on the replication of PCV2 promoted by OTA. The ATG5 protein is necessary for the formation and maturation of autophagosome, ${ }^{48,49}$ whereas Beclin-1 is an essential autophagy protein that regulates the initiation of autophagy and autophagosome-lysosome fusion by interacting with two protein complexes. Both proteins are necessary for autophagy to occur. ${ }^{50,51}$ Depletion of ATG5 and Beclin-1 proteins dramatically suppressed the formation of OTA-induced autophagosomes and attenuated the promotion of PCV2 induced by OTA. 
The results are consistent with those of previous studies in which it was demonstrated that suppression of ATG5 and Beclin-1 with siRNAs reduced the replication of dengue virus, influenza A virus, and PCV2. ${ }^{13,15,52}$
Accumulating evidence suggests that ROS and oxidative stress play a critical role in viral infection. ${ }^{53,54}$ We previously found that oxidative stress can enhance PCV2 infection and that OTA can induce oxidative stress and thereby promote
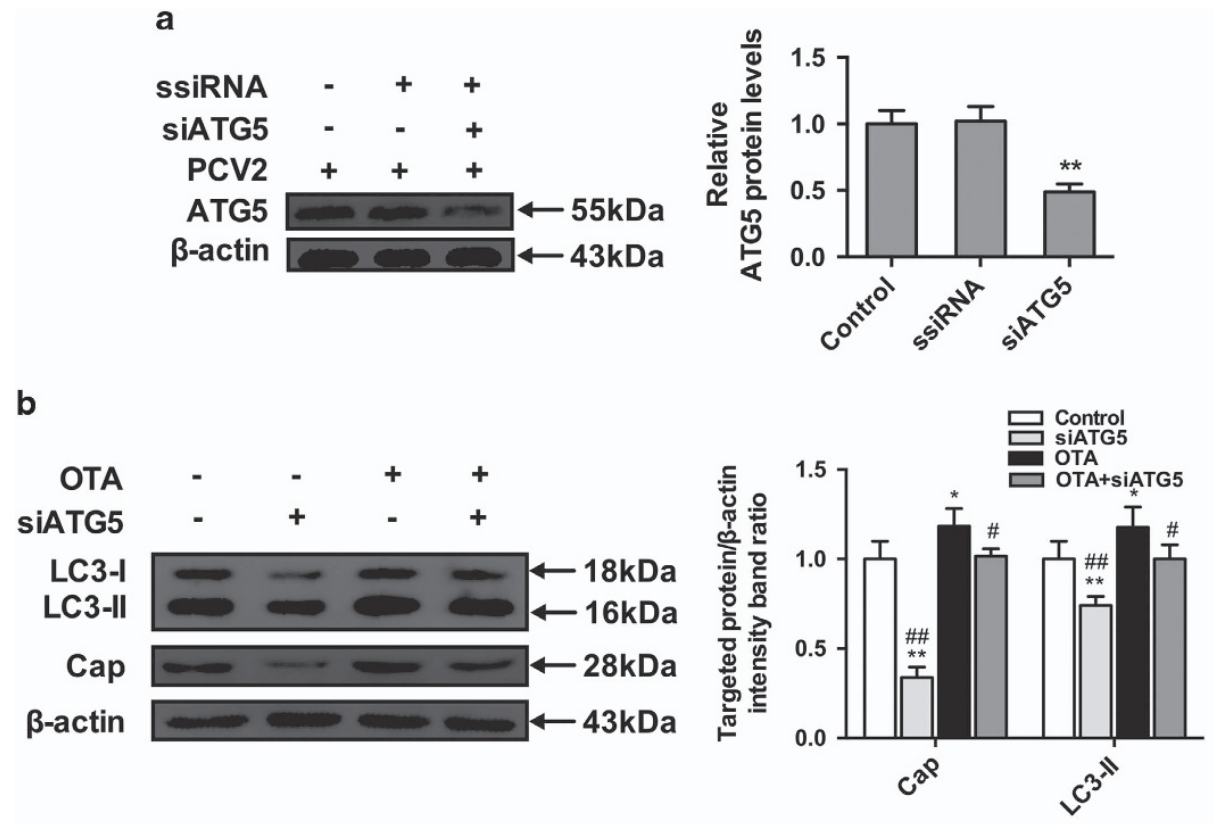

C
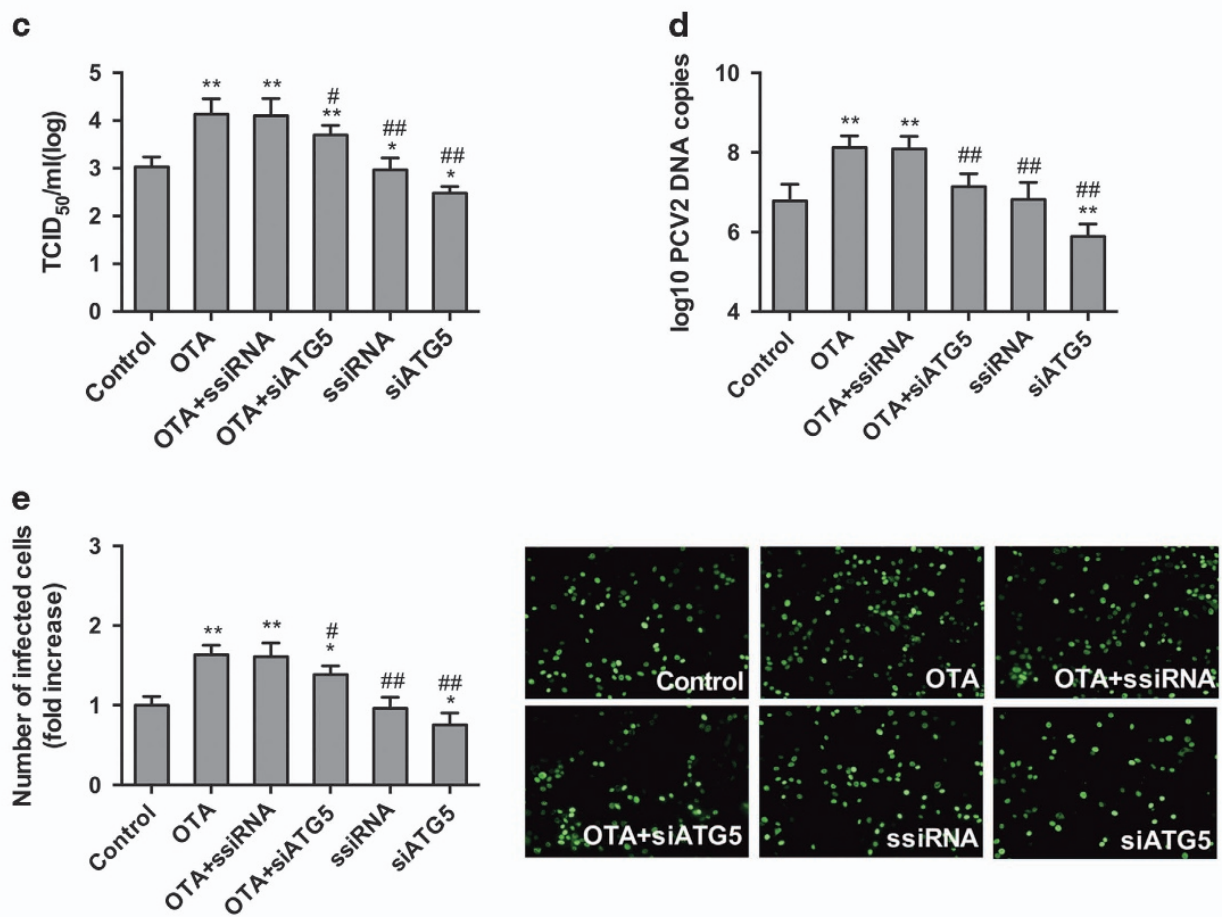

Figure 7 Inhibition of autophagy with siATG5 reverses the PCV2 replication promotion induced by OTA in PK-15 cells. PCV2-infected cells were incubated with or without ATG5 siRNA. The cells were then assayed for the expression levels of (a) ATG5 and $\beta$-actin (loading control). The data are presented as means \pm S.E. of three independent experiments. Statistical significance compared with the control is indicated by ${ }^{*} P<0.05$ and ${ }^{*} P<0.01$. PCV2-infected cells were transfected with ATG5-specific siRNA or a control siRNA and incubated with OTA $(0.1 \mu \mathrm{M})$ for $48 \mathrm{~h}$. Cells were assayed for (b) expression levels of LC3, Cap and $\beta$-actin (loading control), (c) PCV2 viral titers, (d) PCV2 viral DNA copies, and (e) the number of infected cells, as described in Materials and Methods. The data are presented as means \pm S.E. of three independent experiments. Statistical significance compared with the control is indicated by ${ }^{*} P<0.05$ and ${ }^{* *} P<0.01$. Statistical significance compared with OTA is indicated by ${ }^{\sharp} P<0.05$ and $\# P<0.01$ 
a

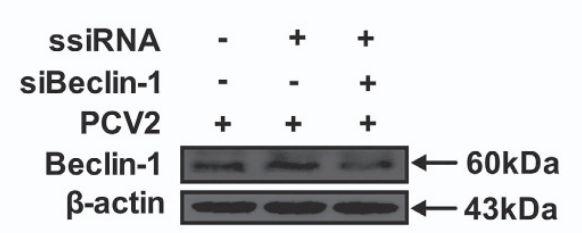

b

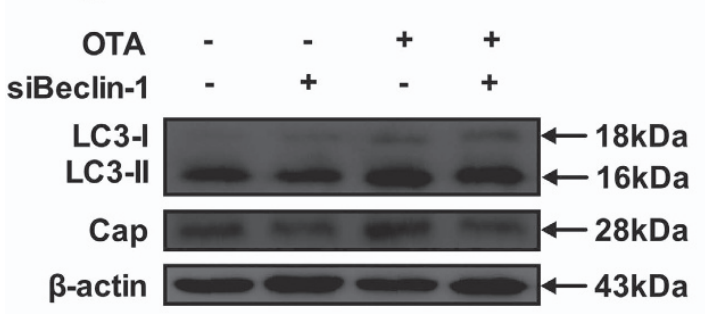

C
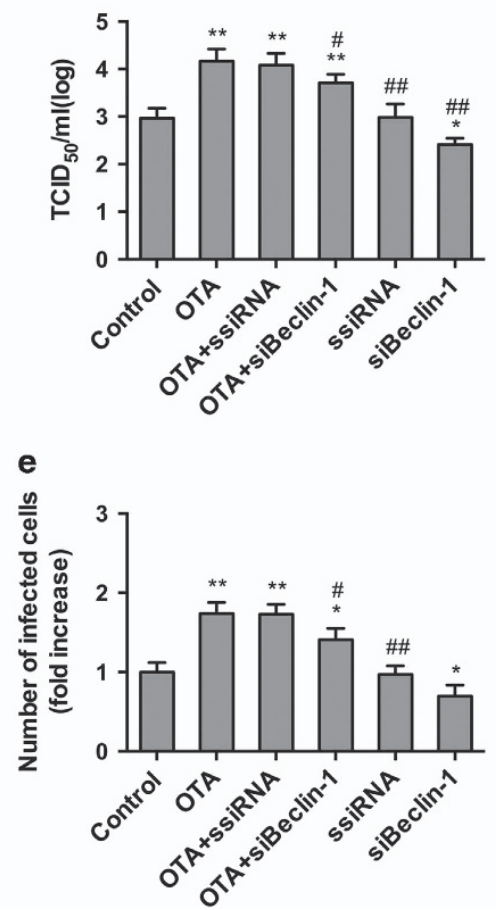
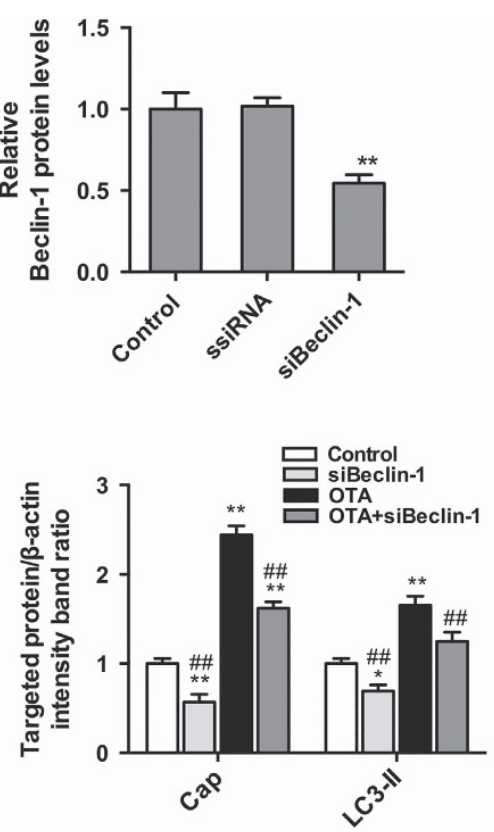

d

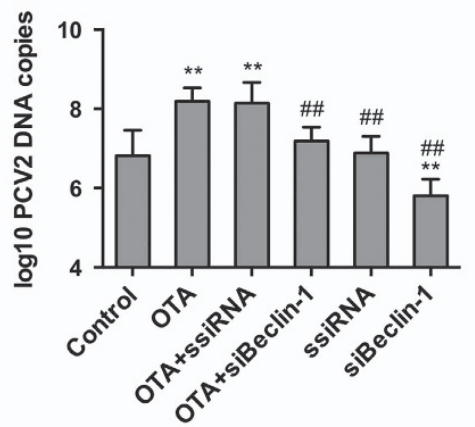

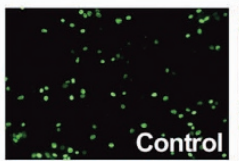
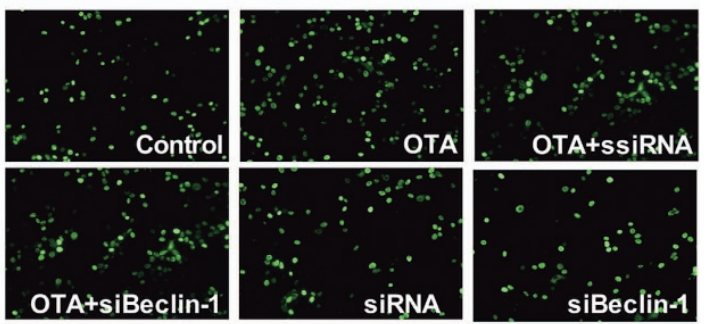

Figure 8 Inhibition of autophagy with siBeclin-1 reverses the PCV2 replication promotion induced by OTA in PK-15 cells. PCV2-infected cells were incubated with or without Beclin-1 siRNA. Cell were assayed for expression levels of (a) Beclin-1 and $\beta$-actin (loading control). The data are presented as means \pm S.E. of three independent experiments. Statistical significance compared with the control is indicated by ${ }^{*} P<0.05$ and ${ }^{\star *} P<0.01$. PCV2-infected cells were transfected with Beclin-1-specific siRNA or a control siRNA and incubated with OTA $(0.1 \mu \mathrm{M})$ for $48 \mathrm{~h}$. Cells were assayed for (b) expression levels of LC3, Cap and $\beta$-actin (loading control), (c) PCV2 viral titers, (d) PCV2 viral DNA copies, and (e) the number of infected cells as described in Materials and Methods. The data are presented as means \pm S.E. of three independent experiments. Statistical significance compared with the control is indicated by ${ }^{*} P<0.05$ and ${ }^{\star \star} P<0.01$. Statistical significance compared with OTA is indicated by ${ }^{\#} P<0.05$ and ${ }^{\# \#} P<0.01$

PCV2 replication. ${ }^{7,55}$ Recently, an increasing body of research has indicated that ROS play an important role in controlling autophagy. ${ }^{56,57}$ Oxidative stress has also been implicated in the mechanisms of OTA-induced cytotoxicity. Previous studies have explored OTA-induced oxidative stress in a variety of cell lines. ${ }^{58,59}$ Therefore, we proposed that autophagy induced by OTA is mediated by the induction of ROS. Indeed, we observed significantly increased levels of ROS after OTA treatment of cells. In addition, we observed that the expression levels of LC3-II, ATG5 and Beclin-1 and OTA-induced 
a
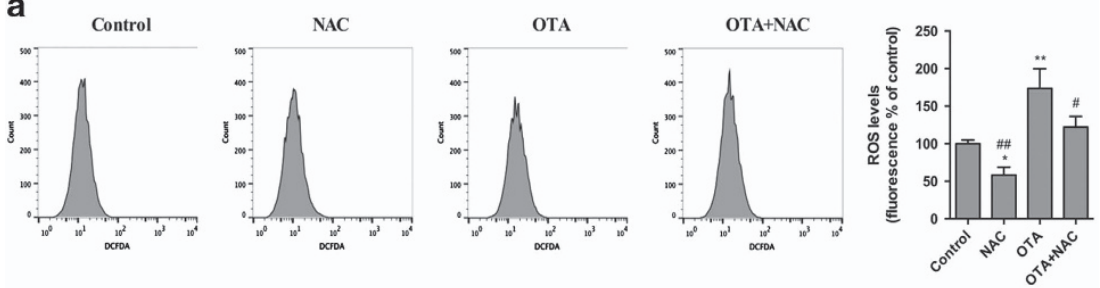

b

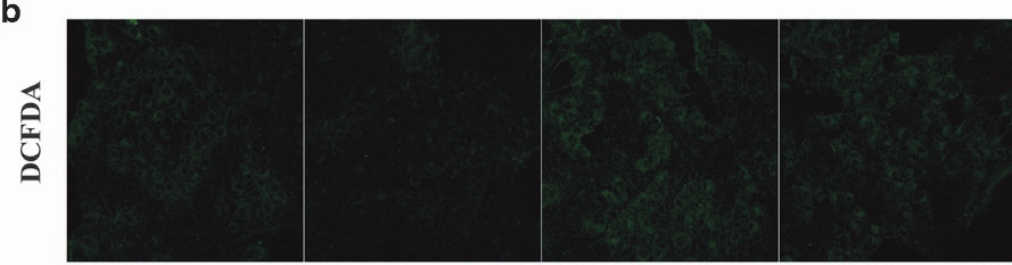

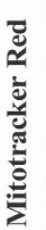
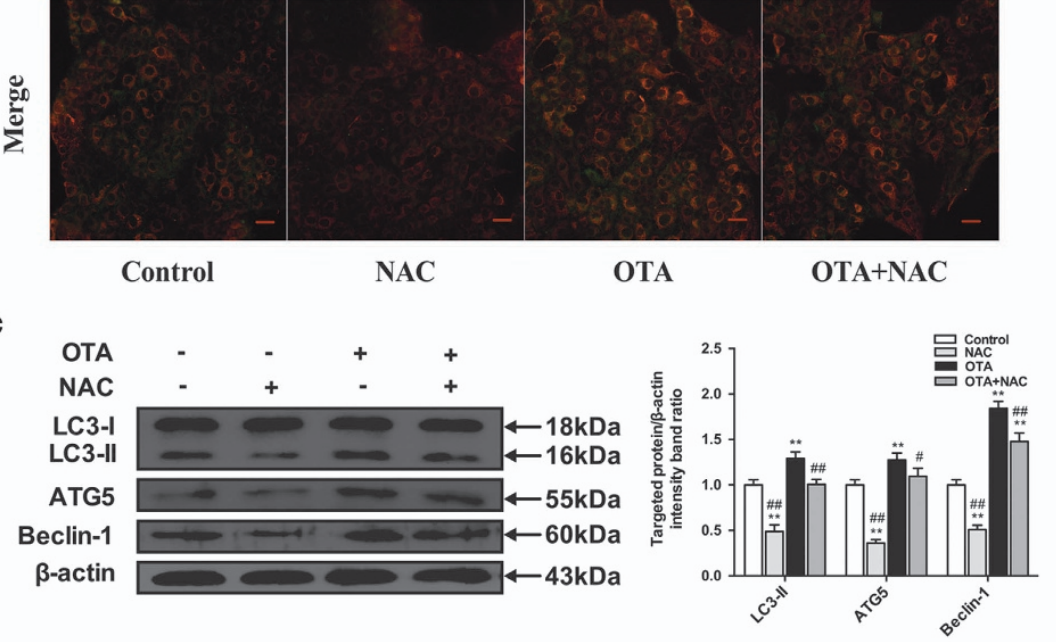

d

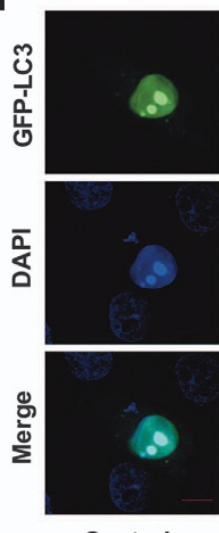

Control
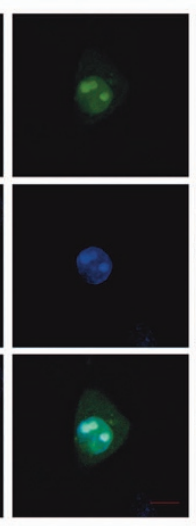

NAC
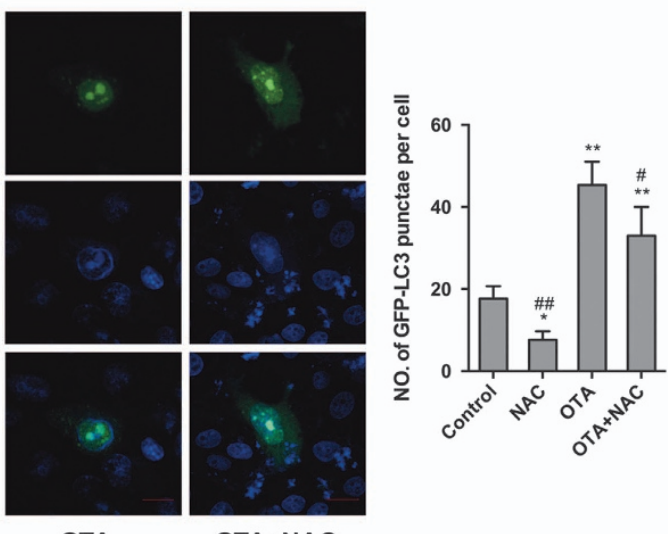

OTA 
GFP-LC3 puncta formation were markedly attenuated when ROS formation was inhibited by NAC. Collectively, our data indicate that OTA triggers oxidative stress and thereby induces autophagy.

During the past few years, numerous in vitro studies have demonstrated the critical role of autophagy in virus infection. However, few studies have been conducted using in vivo models. To corroborate our in vitro results, we evaluated the effects of OTA on PCV2 infection in an animal model and determined whether oxidative stress and autophagy can also be induced in vivo. In the in vivo experiment, pigs were fed diets containing 75 or $150 \mu \mathrm{g} / \mathrm{kg}$ OTA. After such feeding, we observed OTA accumulation in various tissues. The highest concentration of OTA was found in lung tissue, followed by kidney, BLN, liver, inguinal lymph nodes (ILN), and spleen. This is apparently inconsistent with the fact that kidney is generally considered as the target organ for OTA toxicity. ${ }^{60,61}$ However, similar results have also been reported in rats treated with low doses of OTA. ${ }^{62}$ In our experiments, the ranges of OTA concentrations in tissues were $0.05-0.11 \mu \mathrm{g} / \mathrm{g}$ and $0.40-0.69 \mu \mathrm{g} / \mathrm{kg}$ in the animals in the $75 \mu \mathrm{g} / \mathrm{kg}$ OTA and $150 \mu \mathrm{g} / \mathrm{kg}$ OTA treatment groups, respectively. The observed levels of OTA in the tissues of the treated animals are consistent with the concentrations of OTA that promoted PCV2 replication in PK-15 cells in vitro. Our data further showed that treatment of pigs with $75 \mu \mathrm{g} / \mathrm{kg}$ OTA significantly increased PCV2 DNA copies and viral cap protein expression levels in

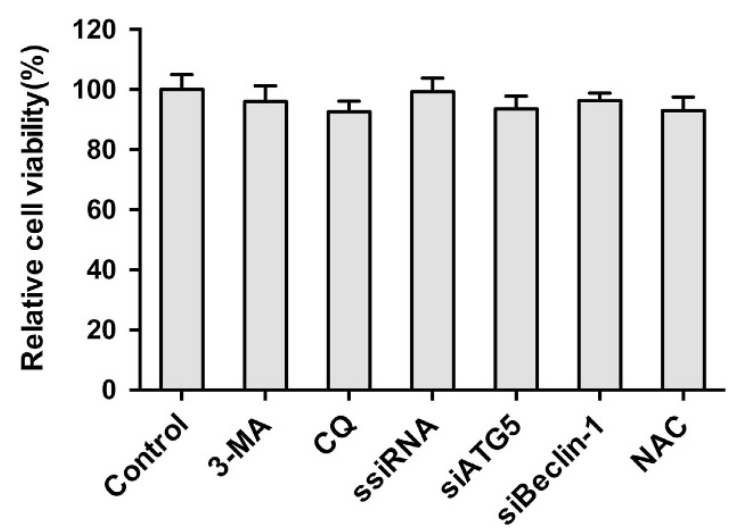

Figure 10 Pharmacological or siRNA alterations of autophagy and NAC does not affect cell viability. Cell viability was determined by MTT assay after treatment of PK-15 cells with 3-MA or CQ or NAC for $48 \mathrm{~h}$ or after transfection with ssiRNA, siATG5 or siBeclin-1 for $48 \mathrm{~h}$. The data are presented as means \pm S.E. of three independent experiments various tissues, including lung, spleen, kidney, and BLN of pigs, a finding that is consistent with our in vitro results showing that relatively low doses of OTA can promote PCV2 replication.

In the present study, the oxidative stress status of pigs was examined. Increased levels of MDA in the serum and decreased serum SOD activities were observed following the treatment of the animals with OTA (Figures 11c and d). In addition, lapidated LC3-II was detected by western blotting in the tissues, and enhanced levels of LC3-II were observed in the lungs, spleens, and kidneys of pigs fed $75 \mu \mathrm{g} / \mathrm{kg}$ OTA and in the BLN of pigs fed with 75 or $150 \mu \mathrm{g} / \mathrm{kg}$ OTA. These results agree to some extent with the viral infectious levels measured in these animals.

Overall, these in vitro results reported here indicate that OTA-induced autophagy is mediated by oxidative stress and that it affects PCV2 replication. The increased levels of oxidative stress and LC3-II observed in the tissues of OTAtreated, PCV2-infected pigs indicate that oxidative stress and autophagy also occur in response to OTA treatment in vivo. These findings increase our knowledge of the pathogenesis of PCV2 and provide new insight into possible methods for the control of PCVAD.

\section{Materials and Methods}

Reagents and antibodies. MTT, 3-MA, CQ, anti-LC3 and HRP-conjugated anti-mouse and anti-rabbit antibodies were purchased from Sigma-Aldrich (St. Louis, MO, USA). NAC, 4',6-diamidino-2-phenylindole and DCFH-DA were purchased from Beyotime Institute of Biotechnology (Haimen, Jiangsu Province, China). Anti-p62, anti-ATG5, anti-Beclin-1, and anti- $\beta$-actin antibodies were purchased from Santa Cruz Biotechnology (Santa Cruz, CA, USA). X-tremeGENE siRNA transfection regent was from Roche (Basel, Switzerland). MitoTracker Red was obtained from Invitrogen (Carlsbad, CA, USA).

Cells, virus, and plasmids. PK-15 cells were provided by the China Institute of Veterinary Drug Control (China) and were free of PCV. PK-15 cells. PK-15 cells were maintained in Dulbecco's minimal Eagle's medium (DMEM; Invitrogen, Carlsbad, CA, USA) containing $8 \%$ fetal bovine serum (FBS; Gibco, Grand Island, NY, USA) and $1 \%$ antibiotics. The cells were cultured at $37^{\circ} \mathrm{C}$ in a humidified atmosphere containing $5 \% \mathrm{CO}_{2}$.

The wild-type PCV2 (PCV2NJ2002) used in the experiments was isolated originally from a kidney tissue sample of a pig with naturally occurring PMWS. The determination of PCV type was performed by sequencing (Invitrogen, Carlsbad, CA, USA). Stocks of PCV2 were generated from PK-15 cells infected with PCV2 as previously described. ${ }^{55}$

To construct pEGFP-LC3B, the LC3B gene was amplified from PK-15 cells using primers (LC3F: 5'-GAAGATCTGGGCTGAGGAGACACAAGAG-3'; LC3R: 5'-CGGAATTCTCTCAGTTGGTAACATCCCTTT-3') that were designed based on the sequence of LC3B (GenBank No. NM 001190290.1). The gene was then cloned into pEGFP-C1 to express LC3B fused with the EGFP protein at its N-terminus.

Figure 9 Effects of OTA and/or NAC on oxidative stress and autophagy in PCV2-infected PK- 15 cells. PK- 15 cells were inoculated with PCV2 for $24 \mathrm{~h}$ and then inculated with OTA $(0.1 \mu \mathrm{M})$, NAC $(5 \mathrm{mM})$, or OTA and NAC together for an additional $48 \mathrm{~h}$. (a) The cells were then incubated with DCFH-DA (10 $\mu \mathrm{M})$ at $37^{\circ} \mathrm{C}$ for 30 min. The level of ROS was determined by flow cytometry. The level of intracellular ROS, which was indicated by an increase in the fluorescence intensity of the cells, was calculated as the percentage of that of the control cells. (b) Representative flourescent staining showing ROS visualized by DCFH-DA fluoreseence (green), and mitochondria labeled by MitoTracker Red CMXRos (red) in PK-15 cells, yellow color (green plus red) indicates the colocalization of ROS and mitochondria. Scale bar: $10 \mu \mathrm{m}$. (c) The cells were collected, and the expression levels of LC3, ATG5, Beclin-1 and $\beta$-actin (loading control) were analyzed by immunoblotting with specific antibodies as described in Materials and Methods. (d) PK-15 cells were first transfected with the GFP-LC3 plasmid. After $24 \mathrm{~h}$, the cells were inoculated with PCV2 for $24 \mathrm{~h}$ and then incubated with OTA $(0.1 \mu \mathrm{M})$, NAC (5 mM), or OTA and NAC together for an additional $48 \mathrm{~h}$. The fluorescence signals were visualized by confocal immunofluorescence microscopy. Scale bar: $10 \mu \mathrm{m}$. The average number of $\mathrm{LC} 3$ puncta in each cell was determined from at least 100 cells in each group. The data are presented as means \pm S.E. of three independent experiments. Statistical significance compared with the control is indicated by ${ }^{*} P<0.05$ and ${ }^{* *} P<0.01$. Statistical significance compared with OTA is indicated by ${ }^{\#} P<0.05$ and ${ }^{\# \#} P<0.01$ 
Virus infection and cell treatment. According to the requirements of individual experiments, PK-15 cells were infected with PCV2 at a multiplicity of infection of 1 at $37^{\circ} \mathrm{C}$. Following a 1 -h absorption period, the cell monolayers were rinsed with sterile phosphate-buffered saline, $\mathrm{pH} 7.2$ (PBS) to remove unattached viruses and then incubated in the presence of fresh medium at $37^{\circ} \mathrm{C}$ for $24 \mathrm{~h}$. Then the cells were then treated with various concentrations of OTA and incubated for an additional $48 \mathrm{~h}$. For autophagy studies, PCV2-infected PK-15 cells were pretreated with 3-MA or $\mathrm{CQ}$ for $4 \mathrm{~h}$ at $37^{\circ} \mathrm{C}$. The cells were then treated as described above and further incubated in fresh medium in the absence or presence of 3-MA and $\mathrm{CQ}$ at the same concentrations as used in the pretreatments or in medium containing a corresponding amount of the solvent DMSO(control), unless otherwise specified in the figure legends.

Cell viability assays. Cell viability was measured using the MTT assay according to the manufacturer's instructions. Briefly, PK-15 cells were cultured in 96-well plates at a density of $5 \times 10^{3}$ cells/well for $24 \mathrm{~h}$ and then subjected to various
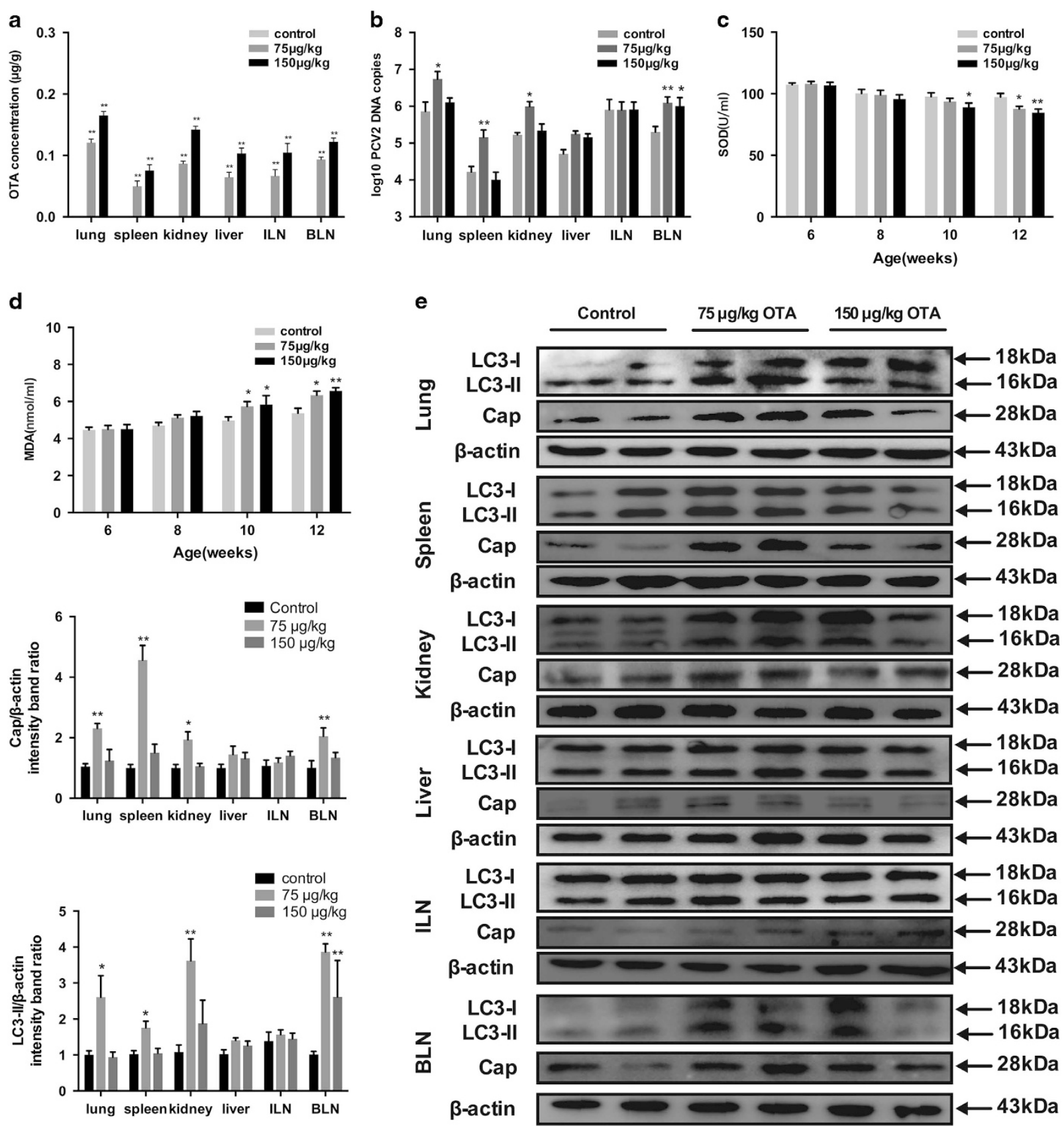

Figure 11 OTA, SOD and MDA concentrations, PCV2 DNA copies and western blotting of LC3 and cap in tissues of pigs fed a basal diet or a basal diet containing OTA at 75 and $150 \mu \mathrm{g} / \mathrm{kg}$. (a) OTA concentrations in lung, spleen, kidney, liver, ILN, and BLN of pigs fed the basal diet (control) or the basal diet with added OTA at 75 and $150 \mu \mathrm{g} / \mathrm{kg}$. (b,c) Levels of (b) SOD and (c) MDA in serum from pigs fed the basal diet (control) or the basal diet containing OTA at 75 or $150 \mu \mathrm{g} / \mathrm{kg}$. (d) PCV2 DNA copies in lung, spleen, kidney, liver, ILN, and BLN of the same pigs were assessed by real-time PCR. (e) The expression levels of LC3 and cap in lung, spleen, kidney, liver, ILN, and BLN of the same pigs were measured by western blotting. The data are presented as means \pm S.E. of three independent experiments. Statistical significance compared with the control is indicated by ${ }^{*} P<0.05$ and ${ }^{* *} P<0.01$ 
treatments for the specified periods. Following treatment, the culture medium was supplemented with $15 \mu \mathrm{l}$ of MTT $(5 \mathrm{mg} / \mathrm{ml})$ for $4 \mathrm{~h}$ at $37^{\circ} \mathrm{C}$. The supernatants were carefully aspirated and replaced with $150 \mu \mathrm{l}$ DMSO to dissolve the precipitate. Absorbance was measured in a microplate reader spectrophotometer at a wavelength of $570 \mathrm{~nm}$. All tests were performed three times.

Detection of cellular ATP levels. Cellular ATP levels were measured using a firefly luciferase-based ATP assay kit (Beyotime, Jiangsu Province, China) according to the manufacturer's instructions. Briefly, PK-15 cells were cultured in 24well plates at a density of $4 \times 10^{4}$ cells/well for $24 \mathrm{~h}$. After treatment with various concentrations of OTA for $48 \mathrm{~h}$, the cells were schizolyzed and centrifuged at $12000 \times g$ for $5 \mathrm{~min}$. Then, $50 \mu \mathrm{l}$ of each supernatant and $50 \mu \mathrm{l}$ of ATP detection working dilution were mixed for $3 \mathrm{~s}$ prior to the measurement of luminescence $10 \mathrm{~s}$ in a GloMax 20/20 luminometer (Promega, Madison, USA). All assays were performed in triplicate.

Quantitative real-time PCR (qRT-PCR). Quantitative real-time PCR (qRTPCR) was performed to determine the PCV2 DNA copies as previously described. ${ }^{55}$ In brief, DNA was extracted using the TaKaRa DNA Mini kit (TaKaRa, China). The purified DNA was used as a template for PCR amplification. A pair of PCV2-specific primers (forward primer 5'-TAGTATTCAAAGGGCACAG-3', reverse primer $5^{\prime}$-AAGGCTACCACAGTCAG- $3^{\prime}$ ) was designed to amplify a 117-bp fragment from the PCV2 ORF2 gene. The qRT-PCR was performed using the ABI Prism Step One Plus detection system (Applied Biosystems, NY, USA). A recombinant pMD19 plasmid vector (TaKaRa) containing a PCV2 genome was used to construct a standard curve, and a TaKaRa SYBR green real-time PCR kit was used to measure the amount of viral DNA.

Indirect immunofluorescence assay. PCV2-infected cells were detected using an indirect immunofluorescence assay (IFA) as previously described. PK-15 cells were washed three times with PBS containing 0.1\% Tween-20 (PBST) and fixed in $4 \%$ paraformaldehyde for $20 \mathrm{~min}$ at room temperature (RT). After three washes in PBST, the cells were permeabilized with $0.1 \%$ Triton $\mathrm{X}-100$ and then incubated in PBST containing $1 \%$ bovine serum albumin (BSA) for $1 \mathrm{~h}$ at $37^{\circ} \mathrm{C}$ to block nonspecific binding. The cells were then incubated with porcine anti-PCV2 antibody (UnivBiotech, Shanghai, China) diluted in PBST containing $1 \%$ BSA (PBSTB; 1:50) for $1 \mathrm{~h}$ at $37^{\circ} \mathrm{C}$, and after three washes with PBST, FITC-conjugated rabbit anti-pig antibody (Sigma; diluted 1:100 in PBST) was added, and the cells were incubated for $1 \mathrm{~h}$ at $37^{\circ} \mathrm{C}$. The cells were again washed three times with PBST, and examined under a fluorescence microscope. Cells positive for PCV2 viral antigens were counted in six fields of view.

Quantification of virus titer. PCV2-infected PK-15 cells grown in six-well plates were pretreated with DMSO or chemicals (3-MA or CQ) for $4 \mathrm{~h}$, or transfected with ssiRNA, siATG5 or siBeclin-1 for $5 \mathrm{~h}$. The cells were then treated with OTA for an additional $48 \mathrm{~h}$. Samples of the culture supernatant samples were collected, and the cells were subjected to three freeze-thaw cycles. Total virus yield (intracellular and extracellular viruses) was determined by inoculating confluent PK-15 cells in 96-well culture plates with 10-fold dilutions of the culture supernatants. After $72 \mathrm{~h}$ of incubation, the viral antigen was detected by IFA as described above. Viral titers were calculated using the Reed-Muench method and expressed as $\mathrm{TCID}_{50} / \mathrm{ml}$.

Cell lysis and western blotting analysis. PK-15 cells cultured in six-well plates were scraped from the plates at the specific times indicated in the figures and collected in cell lysis buffer containing protease inhibitor (Beyotime, Haimen, China) on ice. The cell lysates were sonicated using a Sonics VCX105 sonicator and centrifuged at $12000 \mathrm{rpm}$ for $20 \mathrm{~min}$ at $4{ }^{\circ} \mathrm{C}$. Protein concentration was determined using the BCA protein assay kit (Beyotime). Equal amounts of protein samples were diluted in $5 \times$ SDS-PAGE loading buffer and heated at $95^{\circ} \mathrm{C}$ for $5 \mathrm{~min}$. The samples were separated on $12 \%$ SDS-PAGE gels and transferred to polyvinylidene fluoride membranes. After blocking for $1 \mathrm{~h}$ at RT in Tris-buffered saline containing 5\% nonfat milk powder and $0.1 \%$ Tween 20 , the membranes were incubated with primary antibodies overnight at $4{ }^{\circ} \mathrm{C}$. The membranes were then washed and incubated in secondary antibody at RT for $1 \mathrm{~h}$. Images of the immunoblots were acquired using an EU-88 image scanner (Seiko Epson Corp.). Quantification of protein blots was performed using the Image-Pro Plus 6.0 software (Media Cybernetics).
Confocal fluorescence microscopy. Confocal fluorescence microscopy was used for the analysis of LC3 expression after OTA treatment. Specifically, PK-15 cells grown on coverslips to $40-50 \%$ confluence were transfected with the plasmid GFP-LC3 using X-tremeGENE HP DNA transfection reagent (Roche, Indianapolis, USA) according to the manufacturer's guidelines. The cells were then infected with PCV2 for $24 \mathrm{~h}$ and inoculated with OTA for an additional $48 \mathrm{~h}$ as described above. The intracellular localization of LC3 was visualized using a Nikon C1-si confocal fluorescence microscope (Nikon Instruments, Inc.).

RNA interference. ATG5-specific and Beclin-1-specific siRNAs were designed using the sequence of Sus scrofa ATG5 mRNA (GenBank Accession No. NM_001037152.1) and Beclin-1 mRNA (GenBank Accession No. NM_ 001044530.1), respectively, and Invitrogen BlockiT RNAi designer. Control siRNA sequences were obtained from published material. ${ }^{63}$ The ATG5-specific siRNA sequence was $5^{\prime}$-GCUUCGAGAUGUGUGGUUUtt-3', the Beclin-1-specific siRNA sequence was 5'-CCUGGAUCGUGUUACCAUUtt-3', and the sequence of control siRNA was $5^{\prime}$-UUCUCCGAACGUGUCACGUtt-3'. The three double-stranded RNAs were synthesized by Invitrogen. Duplex RNAs were resuspended in DEPC water to obtain $20 \mu \mathrm{M}$ solutions prior to use. PK-15 cells in DMEM 8\% FBS without antibiotics were seeded in six-well plates at a density of $1 \times 10^{5}$ cells/well and incubated for $24 \mathrm{~h}$ at $37^{\circ} \mathrm{C}$. When the cells were $30-50 \%$ confluent, siRNA was introduced using the X-treameGENE siRNA transfection agent (Roche) according to the protocol provided by the manufacturer. Transfection reagent $(2.5 \mu \mathrm{l})$ and $0.5 \mu \mathrm{g}$ siRNA were added to each well, and the plates were incubated for $5 \mathrm{~h}$. The cells were then washed with DMEM and cultured in DMEM + 4\% FBS until further treatments.

Measurement of intracellular ROS. For the determination of ROS, PK-15 cells were cultured in six-well plates at a density of $1 \times 10^{5}$ cells/well. Intracellular ROS levels were measured using $2^{\prime}, 7^{\prime}$-dichlorofluorescein diacetate (DCFH-DA; Beyotime) as previously described. Briefly, after removing the culture medium, the cells were incubated with DCFH-DA $(10 \mu \mathrm{M})$ at $37^{\circ} \mathrm{C}$ for $30 \mathrm{~min}$. The ROS level was determined by fluorescence microscopy and flow cytometry.

Animal experiments. OTA extracts obtained from in vitro cultures of Aspergillus ochraceus strain (№. 3.4411) were added to the pig basal diet to provide the diets containing 70 and $150 \mu \mathrm{g} / \mathrm{kg}$ OTA.

The experiment was conducted at a 300-sow pig farm. Sixty weaning piglets (age 6 weeks) were selected for the experiment. The average of PCV2 DNA copies in these animals, as measured by real-time PCR, was $10^{3}-10^{5}$ due to natural infection. It was also determined by PCR that the piglets were negative for swine fever virus, swine influenza virus, porcine parvovirus, and porcine reproductive and respiratory syndrome virus. The experiments were conducted in accordance with the standards of the European Guidelines for Animal Welfare and were approved by the Committee for the Care and Use of Experimental Animals of the Nanjing Agricultural University (Animal Ethics Number: SYXK (Su) 2011-0036).

Twenty-seven piglets with an approximately equal body weights of $10.5 \mathrm{~kg}$ were selected, the average of PCV2 DNA copies in each of these animals measured by real-time PCR was $10^{3} .37$ The piglets were randomly divided into three groups, each group included three replicates, with 3 piglets per replicate. Group I, the control group, received a basal diet, groups II and III received the basal diet containing 75 and $150 \mu \mathrm{g} / \mathrm{kg}$ OTA, respectively, for 42 days. The piglets were housed in different rooms under biosafety conditions with ad libitum access to water and feed during the experiment. At the end of the experiment, the piglets were killed, and tissue samples of liver, kidney, spleen, lung, ILN, and BLN were collected. The animal's serum was analyzed for SOD activity and MDA content. Tissue samples were analyzed for OTA concentration and PCV2 DNA copies and the proteins were extracted for western blotting analysis.

Determination of OTA concentration by LC-MS/MS. OTA was extracted from tissues using the method as previously described. Briefly, $1 \mathrm{ml}$ of tissue homogenates was mixed with $5 \mathrm{ml}$ of a methanol/water (80/20) mixture. After vortexing for $2 \mathrm{~min}$, the mixture was sonicated for $1 \mathrm{~h}$, and centrifuged for $15 \mathrm{~min}$ at $3300 \times \mathrm{g}$. The supernatant fluid was transferred to a $10-\mathrm{ml}$ centrifuge tube and dried under nitrogen gas at $50^{\circ} \mathrm{C}$. The residue was reconstituted in $500 \mu \mathrm{l}$ acetonitrile/ water $(20 / 80, v / v)$ containing $10 \mathrm{mmol} / \mathrm{l}$ ammounium acetate, and the resulting solution was passed through a nylon membrance $(0.22 \mu \mathrm{m})$ prior to LC-MS/MS.

One milligram of OTA was dissolved in $5 \mathrm{ml}$ of ethanol to yield a stock solution of $0.5 \mathrm{mg} / \mathrm{ml}$ OTA, which was stored at $-20^{\circ} \mathrm{C}$ in the dark. Standard solutions of OTA were prepared by diluting the stock solution with a mixture of acetonitrile/water 
(20/80, v/v) containing $10 \mathrm{mmol} / \mathrm{l}$ ammonium acetate. A commercially available stock solution of the IS([13C20]-OTA) was diluted with the same solution to $50 \mathrm{ng} / \mathrm{ml}$. All working solutions were prepared immediately before use.

LC-MS/MS (TSQ Quantum Ultra, Thermo Scientific, USA) equipped with electrospray ionization was used for the analysis of OTA, as previously described. ${ }^{7}$

Determination of SOD and MDA levels. The levels of SOD and MDA were detected using specific detection kits obtained from the Nanjing Jiancheng Institute of Biotechnology (Jiancheng, Nanjing, China) according to the manufacturer's instructions. Serum SOD levels are expressed in U/ml, and MDA levels are expressed in $\mathrm{nmol} / \mathrm{ml}$.

Statistical analysis. Statistical analyses were performed using the SPSS computer program for Windows (version 22.0). Data were analyzed for establishing their significance using one-way analysis of variance followed by least-significant difference test. Data are expressed as the mean \pm standard error (S.E.). Differences were regarded as significant at $P<0.05$.

\section{Conflict of Interest}

The authors declare no conflict of interest.

Acknowledgements. We are grateful to Prof. Bin Zhou (Nanjing Agriculture University, Nanjing, China) for providing the plasmid pEGFP-C1. This work was funded by the National Natural Science Foundation of China (NFSC) (31472252 and 31472253), the Fundamental Research Funds for the Central Universities (Y0201500198) and the Priority Academic Program Development of Jiangsu Higher Education Institutions (Jiangsu, China).

1. Tischer I, Gelderblom H, Vettermann W, Koch MA. A very small porcine virus with circular single-stranded DNA. Nature 1982; 295: 64-66.

2. Tomas A, Fernandes LT, Valero O, Segales J. A meta-analysis on experimental infections with porcine circovirus type 2 (PCV2). Vet microbiol 2008; 132: 260-273.

3. Creppy EE. Human ochratoxicosis. J Toxicol-Toxin Rev 1999; 18: 277-293.

4. Pitt J. Penicillium viridicatum, Penicillium verrucosum, and production of ochratoxin A. Appl environ microbiol 1987; 53: 266-269.

5. Jorgensen K. Occurrence of ochratoxin A in commodities and processed food - a review of EU occurrence data. Food addit contam 2005; 22(Suppl 1): 26-30.

6. Wu Q, Dohnal V, Huang L, Kuca K, Wang X, Chen G et al. Metabolic pathways of ochratoxin A. Curr drug metab 2011; 12: 1-10.

7. Gan F, Zhang Z, Hu Z, Hesketh J, Xue H, Chen X et al. Ochratoxin A promotes porcine circovirus type 2 replication in vitro and in vivo. Free rad biol med 2015; 80: 33-47.

8. Kroemer G, Marino G, Levine B. Autophagy and the integrated stress response. Mol cell 2010; 40: 280-293.

9. Yang Z, Klionsky DJ. Eaten alive: a history of macroautophagy. Nat cell biol 2010; 12 814-822.

10. Shintani T, Klionsky DJ. Autophagy in health and disease: a double-edged sword. Science 2004; 306: 990-995.

11. Zhang $Y$, Li Z, Ge X, Guo X, Yang $H$. Autophagy promotes the replication of encephalomyocarditis virus in host cells. Autophagy 2011; 7: 613-628.

12. Liu Q, Qin Y, Zhou L, Kou Q, Guo X, Ge X et al. Autophagy sustains the replication of porcine reproductive and respiratory virus in host cells. Virology 2012; 429: 136-147.

13. Zhou Z, Jiang XJ, Liu D, Fan Z, Hu XD, Yan JG et al. Autophagy is involved in influenza A virus replication. Autophagy 2009; 5: 321-328.

14. Zhu B, Xu F, Li J, Shuai J, Li X, Fang W. Porcine circovirus type 2 explores the autophagic machinery for replication in PK-15 cells. Virus res 2012; 163: 476-485.

15. Heaton NS, Randall G. Dengue virus-induced autophagy regulates lipid metabolism. Cell host microbe 2010; 8: 422-432.

16. Fujita N, Itoh T, Omori H, Fukuda M, Noda T, Yoshimori T. The Atg16L complex specifies the site of LC3 lipidation for membrane biogenesis in autophagy. Mol biol cell 2008; 19: 2092-2100.

17. Kabeya Y, Mizushima N, Ueno T, Yamamoto A, Kirisako T, Noda T et al. LC3, a mammalian homologue of yeast Apg8p, is localized in autophagosome membranes after processing. EMBO j 2000; 19: 5720-5728.

18. Mizushima N, Yamamoto A, Hatano M, Kobayashi Y, Kabeya Y, Suzuki K et al. Dissection of autophagosome formation using Apg5-deficient mouse embryonic stem cells. $J$ cell biol 2001; 152: 657-668.

19. Wang J. Beclin 1 bridges autophagy, apoptosis and differentiation. Autophagy 2008; 4: 947-948.

20. Sun $Q$, Fan W, Chen K, Ding X, Chen S, Zhong Q. Identification of Barkor as a mammalian autophagy-specific factor for Beclin 1 and class III phosphatidylinositol 3-kinase. Proc Nat Acad Sci USA 2008; 105: 19211-19216.

21. Mizushima N, Yoshimori T. How to interpret LC3 immunoblotting. Autophagy 2007; 3: 542-545.
22. Klionsky DJ, Cuervo AM, Seglen PO. Methods for monitoring autophagy from yeast to human. Autophagy 2007; 3: 181-206.

23. Bjorkoy G, Lamark T, Johansen T. p62/SQSTM1: a missing link between protein aggregates and the autophagy machinery. Autophagy 2006; 2: 138-139.

24. Pankiv S, Clausen TH, Lamark T, Brech A, Bruun JA, Outzen $\mathrm{H}$ et al. p62/SQSTM1 binds directly to Atg8/LC3 to facilitate degradation of ubiquitinated protein aggregates by autophagy. J biol chem 2007; 282: 24131-24145.

25. Tanida I, Minematsu-lkeguchi N, Ueno T, Kominami E. Lysosomal turnover, but not a cellular level, of endogenous LC3 is a marker for autophagy. Autophagy 2005; 1: 84-91.

26. Singletary K, Milner J. Diet, autophagy, and cancer: a review. Cancer epidemiol biomarkers prev 2008; 17: 1596-1610.

27. Seglen PO, Gordon PB. 3-Methyladenine: specific inhibitor of autophagic/lysosomal protein degradation in isolated rat hepatocytes. Proc Natl Acad Sci USA 1982; 79: 1889-1892.

28. Petiot A, Ogier-Denis E, Blommaart EF, Meijer AJ, Codogno P. Distinct classes of phosphatidylinositol $3^{\prime}-$ kinases are involved in signaling pathways that control macroautophagy in HT-29 cells. J biol chem 2000; 275: 992-998.

29. Boya P, Gonzalez-Polo RA, Casares N, Perfettini JL, Dessen P, Larochette N et al. Inhibition of macroautophagy triggers apoptosis. Mol cell biol 2005; 25: 1025-1040.

30. Haighton LA, Lynch BS, Magnuson BA, Nestmann ER. A reassessment of risk associated with dietary intake of ochratoxin A based on a lifetime exposure model. Crit rev toxicol 2012; 42: 147-168.

31. Patterson AR, Opriessnig T. Epidemiology and horizontal transmission of porcine circovirus type 2 (PCV2). Anim health res rev 2010; 11: 217-234.

32. Grau-Roma L, Fraile L, Segales J. Recent advances in the epidemiology, diagnosis and control of diseases caused by porcine circovirus type 2 . Vet $j 2011 ; 187: 23-32$.

33. Levine B, Kroemer G. Autophagy in the pathogenesis of disease. Cell 2008; 132: 27-42.

34. Guo $X$, Dong $Y$, Yin $S$, Zhao $C$, Huo Y, Fan $L$ et al. Patulin induces pro-survival functions via autophagy inhibition and p62 accumulation. Cell death dis 2013; 4: e822.

35. Tallóczy Z, Th VH, Levine B. PKR-dependent autophagic degradation of herpes simplex virus type 1. Autophagy 2006; 2: 24.

36. Liang XH, Kleeman LK, Jiang HH, Gordon G, Goldman JE, Berry G et al. Protection against fatal Sindbis virus encephalitis by Beclin, a novel Bcl-2-interacting protein. J virol 1998; 72 : 8586-8596.

37. Wang $Y$, Zheng $W$, Bian $X$, Yuan $Y, G u J$, Liu $X$ et al. Zearalenone induces apoptosis and cytoprotective autophagy in primary Leydig cells. Toxicol lett 2014; 226: 182-191.

38. Shen XL, Zhang B, Liang R, Cheng WH, Xu W, Luo $Y$ et al. Central role of Nix in the autophagic response to ochratoxin A. Food chem toxicol 2014; 69: 202-209.

39. Mwanza M, Kametler L, Bonai A, Rajli V, Kovacs M, Dutton MF. The cytotoxic effect of fumonisin B1 and ochratoxin A on human and pig lymphocytes using the Methyl Thiazol Tetrazolium (MTT) assay. Mycotoxin res 2009; 25: 233-238.

40. Klaric MS, Zeljezic D, Rumora L, Peraica M, Pepeljnjak S, Domijan AM. A potential role of calcium in apoptosis and aberrant chromatin forms in porcine kidney PK15 cells induced by individual and combined ochratoxin A and citrinin. Arch toxicol 2012; 86: 97-107.

41. Bjorkoy G, Lamark T, Brech A, Outzen H, Perander M, Overvatn A et al. p62/SQSTM1 forms protein aggregates degraded by autophagy and has a protective effect on huntingtin-induced cell death. J cell biol 2005; 171: 603-614.

42. Dreux M, Gastaminza P, Wieland SF, Chisari FV. The autophagy machinery is required to initiate hepatitis C virus replication. Proc Natl Acad Sci USA 2009; 106: 14046-14051.

43. Yoon SY, Ha YE, Choi JE, Ahn J, Lee H, Kweon HS et al. Coxsackievirus B4 uses autophagy for replication after calpain activation in rat primary neurons. J virol 2008; 82: 11976-11978.

44. Taylor MP, Kirkegaard K. Modification of cellular autophagy protein LC3 by poliovirus. J virol 2007; 81: 12543-12553.

45. Wu Y, Wang X, Guo H, Zhang B, Zhang XB, Shi ZJ et al. Synthesis and screening of 3-MA derivatives for autophagy inhibitors. Autophagy 2013; 9: 595-603.

46. Palmeira dos Santos C, Pereira GJ, Barbosa CM, Jurkiewicz A, Smaili SS, Bincoletto C. Comparative study of autophagy inhibition by $3 \mathrm{MA}$ and $\mathrm{CQ}$ on Cytarabineinduced death of leukaemia cells. J cancer res 2014; 140: 909-920.

47. Sun Y, Yu S, Ding N, Meng C, Meng S, Zhang S et al. Autophagy benefits the replication of Newcastle disease virus in chicken cells and tissues. $J$ virol 2014; 88: 525-537.

48. Matsushita M, Suzuki NN, Obara K, Fujioka Y, Ohsumi Y, Inagaki F. Structure of Atg5.Atg16, a complex essential for autophagy. J biol chem 2007; 282: 6763-6772.

49. Codogno P, Meijer AJ. Atg5: more than an autophagy factor. Nature cell biol 2006; 8: 1045-1047.

50. Sun Q, Fan W, Zhong Q. Regulation of Beclin 1 in autophagy. Autophagy 2009; 5: 713-716.

51. Liang XH, Jackson S, Seaman M, Brown K, Kempkes B, Hibshoosh $\mathrm{H}$ et al. Induction of autophagy and inhibition of tumorigenesis by beclin 1. Nature 1999; 402: 672-676.

52. Zhou Z, Jiang X, Liu D, Fan Z, Hu X, Yan J et al. Autophagy is involved in influenza A virus replication. Autophagy 2009; 5: 321-328.

53. Kavouras JH, Prandovszky E, Valyi-Nagy K, Kovacs SK, Tiwari V, Kovacs M et al. Herpes simplex virus type 1 infection induces oxidative stress and the release of bioactive lipid peroxidation by-products in mouse P19N neural cell cultures. J neurovirol 2007; 13: 416-425.

54. Aubert M, Chen Z, Lang R, Dang CH, Fowler C, Sloan DD et al. The antiapoptotic herpes simplex virus glycoprotein $\mathrm{J}$ localizes to multiple cellular organelles and induces reactive oxygen species formation. J virol 2008; 82: 617-629.

55. Chen X, Ren F, Hesketh J, Shi X, Li J, Gan F et al. Reactive oxygen species regulate the replication of porcine circovirus type 2 via NF-kappaB pathway. Virology 2012; 426: 66-72. 
56. Lin WJ, Kuang HY. Oxidative stress induces autophagy in response to multiple noxious stimuli in retinal ganglion cells. Autophagy 2014; 10: 1692-1701.

57. Dewaele M, Maes H, Agostinis P. ROS-mediated mechanisms of autophagy stimulation and their relevance in cancer therapy. Autophagy 2010; 6: 838-854.

58. Shen XL, Zhang Y, Xu W, Liang R, Zheng J, Luo Y et al. An iTRAQ-based mitoproteomics approach for profiling the nephrotoxicity mechanisms of ochratoxin A in HEK 293 cells. $J$ proteom 2013; 78: 398-415.

59. Zheng J, Zhang Y, Xu W, Luo Y, Hao J, Shen XL et al. Zinc protects HepG2 cells against the oxidative damage and DNA damage induced by ochratoxin A. Toxicol Appl Pharmacol 2013; 268: 123-131.

60. Ferrufino-Guardia EV, Tangni EK, Larondelle Y, Ponchaut S. Transfer of ochratoxin A during lactation: exposure of suckling via the milk of rabbit does fed a naturally-contaminated feed. Food add contam 2000; 17: 167-175.

61. Pleadin J, Kudumija N, Kovacevic D, Scortichini G, Milone S, Kmetic I. Comparison of ochratoxin A levels in edible pig tissues and in biological fluids after exposure to a contaminated diet. Mycotoxin res 2016; 32: 145-151.

62. Han Z, Zhao Z, Shi J, Liao Y, Zhao Z, Zhang D et al. Combinatorial approach of LC-MS/MS and LC-TOF-MS for uncovering in vivo kinetics and biotransformation of ochratoxin $A$ in rat. J chromatogr B 2013; 925: 46-53.
63. Zhu B, Zhou Y, Xu F, Shuai J, Li X, Fang W. Porcine circovirus type 2 induces autophagy via the AMPK/ERK/TSC2/mTOR signaling pathway in PK-15 cells. J virol 2012; 86: 12003-12012

(c) Cell Death and Disease is an open-access journal published by Nature Publishing Group. This work is licensed under a Creative Commons Attribution 4.0 International License. The images or other third party material in this article are included in the article's Creative Commons license, unless indicated otherwise in the credit line; if the material is not included under the Creative Commons license, users will need to obtain permission from the license holder to reproduce the material. To view a copy of this license, visit http://creativecommons.org/licenses/by/4.0/

(C) The Author(s) 2017 